\title{
Spectrum of neurological complications following COVID-19 vaccination
}

\author{
Ravindra Kumar Garg ${ }^{1}\left[\right.$ Dimal Kumar Paliwal ${ }^{2} \mathbb{D}$
}

Received: 4 August 2021 / Accepted: 8 October 2021 / Published online: 31 October 2021

(c) Fondazione Società Italiana di Neurologia 2021

\begin{abstract}
COVID-19 vaccines have brought us a ray of hope to effectively fight against deadly pandemic of COVID-19 and hope to save lives. Many vaccines have been granted emergency use authorizations by many countries. Post-authorization, a wide spectrum of neurological complications is continuously being reported following COVID-19 vaccination. Neurological adverse events following vaccination are generally mild and transient, like fever and chills, headache, fatigue, myalgia and arthralgia, or local injection site effects like swelling, redness, or pain. The most devastating neurological post-vaccination complication is cerebral venous sinus thrombosis. Cerebral venous sinus is frequently reported in females of childbearing age, generally following adenovector-based vaccination. Another major neurological complication of concern is Bell's palsy that was reported dominantly following mRNA vaccine administration. Acute transverse myelitis, acute disseminated encephalomyelitis, and acute demyelinating polyneuropathy are other unexpected neurological adverse events that occur as result of phenomenon of molecular mimicry. Reactivation of herpes zoster in many persons, following administration of mRNA vaccines, has been also recorded. Considering the enormity of recent COVID-19-vaccinated population, the number of serious neurological events is miniscule. Large collaborative prospective studies are needed to prove or disprove causal association between vaccine and neurological adverse events occurring vaccination.
\end{abstract}

Keyword COVID-19; SARS-COV-2; Vaccination; Cerebral venous sinus thrombosis; Thrombocytopenia

SARS-CoV-2 is a novel coronavirus that can rapidly affect human beings and can result in coronavirus disease (COVID-19). COVID-19 is dominantly characterized by lung damage and hypoxia. The first case of COVID-19, in Wuhan, China, was reported on December 8, 2019. Later, the World Health Organization announced COVID-19 as a worldwide health emergency, on January 30, 2020. On March 11, 2020, COVID-19 was declared a pandemic. As per the latest World Health Organization report, there were 196,553,009 confirmed cases as on August 1, 2021 along with 4,200,412 deaths [1].

Ravindra Kumar Garg

garg50@yahoo.com

Vimal Kumar Paliwal

dr_vimalkpaliwal@rediffmail.com

1 Department of Neurology, King George Medical University, Lucknow, Uttar Pradesh, India PIN-226003

2 Department of Neurology, Sanjay Gandhi Postgraduate Institute of Medical Sciences, Rae Bareli road, Lucknow, India
Early this year, COVID-19 vaccines has brought a ray of hope to effectively fight against this deadly pandemic and save precious human lives. Currently, four major vaccine types are being used. These vaccine types include viral vector-based vaccines, COVID-19 mRNA-based vaccines, inactivated or attenuated virus vaccine, and protein-based vaccines. In viral vector-based vaccines, adenovirus is used to deliver a part of SARS-COV-2 genome to human cells. Human cells use this genetic material to produce SARSCOV-2 spike protein. Human body recognizes this protein to start a defensive response. The mRNA-based vaccines consist of SARS-COV-2 RNA. Once introduced, genetic material helps in making SARS-COV-2-specific protein. This protein is recognized by human body to start defensive immune reaction. In inactivated or attenuated vaccines, killed or attenuated SARS-COV-2 virus triggers immune response. Protein-based vaccines use the spike protein or its fragments for inciting immune response. These COVID19 vaccines have received emergency approvals in different countries for human use [2]. As per the latest World Health Organization report, until August 1, 2021, globally, a total 
of 3,839,816,037 COVID-19 vaccine doses have been globally administered [1].

In fact, all kinds of vaccines are associated with the risk of several serious neurological complications, like acute disseminated encephalomyelitis, transverse myelitis, aseptic meningitis, Guillain-Barré syndrome, macrophagic myofasciitis, and myositis. Influenza vaccine has been found associated with narcolepsy in young persons. Several pathogenic mechanisms, like molecular mimicry, direct neurotoxicity, and aberrant immune reactions, have been ascribed to explain these vaccines associated with neurological complications [3]. Even COVID-19 vaccines are not free from neurological complications. In this article, we have focused on the neurological complications following COVID-19 vaccination that were reported after their emergency use authorizations.

\section{Search strategy}

We reviewed available data regarding neurological complications (post-authorization) described following the World Health Organization-approved COVID-19 vaccination. We classified COVID-19 vaccination associated with neurological complications in two broad groups: (1) common but mild and (2) rare but severe. We searched PubMed, Google, and Google Scholar databases using the keywords "COVID-19" or "SARS-CoV-2" and "vaccination" or "vaccine," to identify all published reports on neurological complications of COVID-19 vaccines. We in this review will focus on spectrum of published neurological adverse events following COVID-19 vaccination. Last search was done on August $1,2021$.

\section{Mild neurological events}

Neurological adverse events following COVID-19 vaccination are generally mild and transient, like fever/chills, headache, fatigue, myalgia and arthralgia, or local injection site effects like swelling, redness, or pain. These mild neurological symptoms are common following administration of all kinds of COVID-19 vaccines.

Anxiety-related events, like feeling of syncope and/or dizziness, are particularly common. For example, Centers for Disease Control and Prevention, in a report published on April 30, 2021, recorded 64 anxiety-related events (syncope in 17) among 8,624 Janssen COVID-19 vaccine recipients. None of the event was labeled as serious [4].

In Mexico (data available in form of preprint) among 704 003 subjects who received first doses of the Pfizer-BioNTech mRNA COVID-19 vaccine, 6536 adverse events following immunization were recorded. Among those, 4258 (65\%) had at least one neurologic manifestation, mostly (99.6\%) mild and transient. These events included headache $(62.2 \%)$, transient sensory symptoms (3.5\%), and weakness (1\%). In this study, there were only 17 serious adverse events, seizures (7), functional syndromes (4), Guillain-Barré syndrome (3), and transverse myelitis (2) [5].

In South Korea, Kim and co-workers collected data of post-vaccination adverse events following first dose of adenovirus vector vaccine ChAdOx1 nCoV-19 (1,403 subjects) and mRNA vaccine BNT162b2 (80 subjects) vaccinations. Data were collected daily for 7 days after vaccination. Authors noted that $91 \%$ of adenovirus-vectored vaccine and $53 \%$ of mRNA vaccine recipients had mild adverse reactions, like injection-site pain, myalgia, fatigue, headache, and fever [6]. A mobile-based survey among healthcare workers (265 respondents) who received both doses of the BNT162b2 mRNA vaccine was conducted. The most common adverse effects were muscle ache, fatigue, headache, chills, and fever. Adverse reactions were higher after the second dose compared with that after the first dose [7].

\section{Headache}

Headache is one of the most frequent mild neurological complaints reported by a large number of COVID-19 vaccine recipients, soon after they receive vaccine.

A review of headache characteristic noted that among 2464 participants, headache begun $14.5 \pm 21.6 \mathrm{~h}$ after AstraZeneca adenovirus vector vaccine COVID-19 vaccination and persisted for $16.3 \pm 30.4 \mathrm{~h}$. Headaches, in majority, were moderate to severe in intensity and generally localized to frontal region. Common accompanying symptoms were fatigue, chills, exhaustion, and fever [8]. In a multicenter observational cohort study, Göbel et al. recorded clinical characteristic of headache occurring after the mRNA BNT162b2 mRNA COVID-19 vaccination. Generally, headache started $18.0 \pm 27.0 \mathrm{~h}$ after vaccination and persisted for $14.2 \pm 21.3 \mathrm{~h}$. In majority, the headaches were bifrontal or temporal, dull aching character and were moderate to severe in intensity. The common accompanying symptoms were fatigue, exhaustion, and muscle pain [8].

\section{Severe neurological adverse events}

Serious adverse reaction following immunization is defined as a post-vaccination event that are either life-threatening, requires hospitalization, or result in severe disability. The World Health Organization listed Guillain-Barré syndrome, seizures, anaphylaxis, syncope, encephalitis, thrombocytopenia, vasculitis, and Bell's palsy as serious neurologic adverse events. Instances of serious adverse events following COVID-19 vaccinations are continuously pouring in the 
current scientific literature and are source of vaccine hesitancy in many persons [9] (Fig. 1).

\section{Functional neurological disorders}

Functional neurological disorders are triggered by physical/ emotional stress following an injury, medical illness, a surgery, or vaccination. Functional neurological disorders often remain misdiagnosed despite extensive workup.

After availability of COVID-19 vaccine, many YouTube videos depicted continuous limb and trunk movements and difficulty walking immediately after COVID-19 vaccine administration. These videos were of concern as they were the source of "vaccine hesitancy" [10]. Kim and colleagues reviewed several such social media videos demonstrating motor movements consistent with functional motor symptoms occurring after administration of COVID-19 vaccine. Motor movements were bizarre asynchronous and rapidly variable in frequency and amplitude consistent with functional neurological disorder. The Functional Neurological Disorder Society has lately clarified that movement disorder is consistent with functional in nature. The spread of these videos are important because these functional disorders created concerns for vaccine hesitancy [11].

Several other kinds of functional neurological disorders have also been reported. Butler and colleagues described two young ladies, who presented with functional motor deficits mimicking stroke. Both these patients had variability in weakness and had many non-specific symptoms. A detailed workup and neuroimaging failed to demonstrate any specific abnormality [12]. Ercoli and colleagues described a middle-aged man who, immediately after vaccine administration, reported bilateral facial paralysis along with failure to blink. These manifestations resolved quickly within $40 \mathrm{~min}$. Immediately after administration of second dose of vaccine, he complained of respiratory distress and swollen tongue. Again, all these symptoms resolved quickly following treatment with corticosteroids, however, he developed new symptoms in the form of right hemiparesis. Two weeks later, he developed facial hypoesthesia. A detailed workup of the patient failed to demonstrate any abnormality. A diagnosis of functional neurological disorder was, finally, made [13].

\section{Cerebral vascular events}

As a matter of concern, increasing number of reports about adenoviral vector vaccine-induced cerebral vascular adverse events, like cerebral venous thrombosis, arterial stroke, and intracerebral hemorrhage, is getting published in leading medical journals. These reports are alarming as post-vaccination vascular events culminate either in severe disability or death. Vaccine-induced cerebral vascular adverse events are generally associated with severe immune-mediated thrombotic thrombocytopenia. Thrombocytopenia generally clinically manifests within 5 to 30 days after administration of adenovirus vector-based vaccines. In post-vaccination thrombotic thrombocytopenia, a picture similar to that of heparin-induced thrombocytopenia is encountered. When heparin binds platelet factor 4 , there is generation of antibodies against platelet factor 4 . Antibodies against platelet factor 4 result in platelet destruction and trigger the intravascular blood clotting [14]. The post-mortem examination, in patients with vaccine-induced thrombocytopenia, demonstrated extensive involvement of large venous vessels. Microscopic findings showed vascular thrombotic occlusions occurring in the vessels of multiple body organs along with marked inflammatory infiltration [15]. The vector-based vaccines contain genetic material of SARS-COV-2 that is capable of encoding the spike glycoprotein. Possibly, leaked
Fig. 1 A flow diagram depicts the spectrum of severe neurological complications following COVID-19 vaccinations (ADEM, acute disseminated encephalomyelitis; CVST, cerebral venous sinus thrombosis; LETM, longitudinally extensive transverse myelitis; MS, multiple sclerosis; NMOSD, neuromyelitis optica spectrum disorders; PRES, posterior reversible encephalopathy syndrome; TIA, transient ischemic attacks)

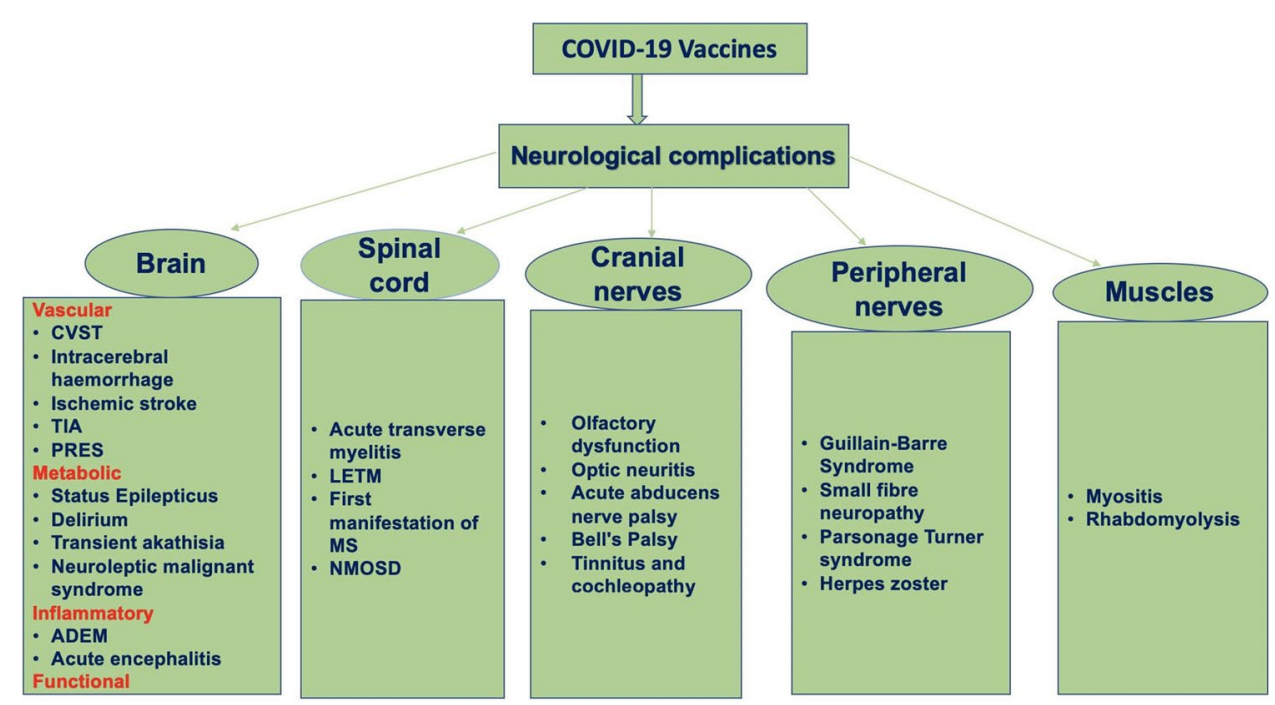


genetic material binds to platelet factor 4 that subsequently activates formation of autoantibodies. These autoantibodies destroy platelets $[16,17]$.

\section{Cerebral venous thrombosis}

Cerebral venous thrombosis is the one of the most feared devastating COVID-19 vaccine-associated neurological complication. Cerebral venous thrombosis should be suspected in all vaccinated patients, who has persistent headache. Headache is generally unresponsive to the analgesics, and some patients may have focal neurological deficits. Affected patients are generally females of younger ages (Table 1) [18-46].

In Europe, since March 2021, cases of cerebral venous thrombosis started pouring in following COVID-19 vaccination, particularly after administration of viral vector based (AstraZeneca ChAdOx1 nCoV-19 and the Johnson and Johnson Ad26. COV2.S) vaccines [22]. Scully and colleagues recently reported findings of 23 patients, who presented with thrombosis and thrombocytopenia (platelet counts below $10 \times 109 / \mathrm{L}$ ). These patients developed thrombosis and thrombocytopenia 6 to 24 days after they received the first dose of the viral vector-based vaccines. In a significant observation, authors, in majority of patients, demonstrated the presence of autoantibodies against platelet factor 4. Additionally, D-dimer levels were found elevated [20]. Tiede and co-workers reported five German cases of prothrombotic immune thrombocytopenia after vaccination with viral vector-based vaccine (Vaxzevria). In these patients, acute vascular events clinically manifested as cerebral venous sinus thrombosis, splanchnic vein thrombosis, arterial cerebral thromboembolism, and/or thrombotic microangiopathy within 2 weeks post vaccination. All five patients had low platelet counts and markedly raised D-dimer. In all, autoantibodies against platelet factor 4 were also demonstrated [30].

Pottegård et al. in Denmark and Norway evaluated incidence of arterial events, venous thromboembolism, thrombocytopenia, and bleeding among vaccinated population. The vaccinated cohorts comprised of 148,792 Danish people and 132,472 persons from Norway. All has received their first dose of viral vector-based vaccine (ChAdOx1-S). An excess rate of venous thromboembolism (like cerebral venous thrombosis) was observed among vaccine recipients, within 28 days of vaccine administration. Authors estimated an increased rate for venous thromboembolism corresponding to 11 excess events per 100,000 vaccinations with 2.5 excess cerebral venous thrombosis events per 100,000 vaccinations [47].

Krzywicka et al., from the Netherlands, collected data of 213 cases with post-vaccination (187 after adenoviral vector vaccines and 26 after a mRNA vaccine) cerebral venous sinus thrombosis; they noted thrombocytopenia in 107/187 (57\%) post-vaccination cerebral venous sinus thrombosis cases. Thrombocytopenia was not recorded in any of patients, who received an mRNA-based vaccine. Cerebral venous sinus thrombosis after adenoviral vector vaccines carried poorer prognosis. Approximately, 38\% (44/117) patients in adenoviral vector vaccine group died, while in mRNA vaccine group, 20\% (2/10) had died [48].

Recently published National Institute for Health and Care Excellence (NICE) guidelines recommend that the patients with clinical diagnosis of vaccine-induced immune thrombocytopenia and thrombosis should be treated with intravenous administration of human immunoglobulin, at a dose of $1 \mathrm{~g} /$ $\mathrm{kg}$. If there is no response or there is further deterioration, second dose of human immunoglobulin should be given. In patients with insufficient response, methylprednisolone $1 \mathrm{~g}$ intravenously for 3 days or dexamethasone 20 to $40 \mathrm{mg}$ for 4 days can be used [49].

Heparin needs to be avoided, instead alternative anticoagulants like argatroban, bivalirudin, fondaparinux, rivaroxaban, or apixaban should be used for anticoagulation [49-51]. NICE guidelines further recommend that patients with very low platelet count should be treated either alone with a argatroban or a combination of argatroban and platelet transfusion [49].

\section{Arterial events}

Several acute arterial events, like arterial thrombosis, intracerebral hemorrhage, transient global amnesia, and spinal artery ischemia, have also been reported following vaccination [31].

Simpson and colleagues, in Scotland, estimated the incidence of vaccine-associated thrombocytopenia and vascular events following administration of first dose of viral vectorbased vaccine (ChAdOx1) or mRNA (BNT162b2 PfizerBioNTech or mRNA-1273 Moderna) vaccination. First dose of viral vector-based vaccine was associated with small enhanced risk of idiopathic thrombocytopenic purpura; in addition, up to 27 days after vaccination, there was possibility of an increased risk for thromboembolic and hemorrhagic events. No such adverse associations were noted with mRNA vaccines [52]. The reports of COVID-19 vaccine-related intracerebral hemorrhage and ischemic stroke are summarized in Table 2 [53-61].

\section{Intracerebral hemorrhage}

Athyros and Doumas reported a 71-year-old female. who developed intracerebral hemorrhage after she received the first dose of the Moderna mRNA vaccine. 


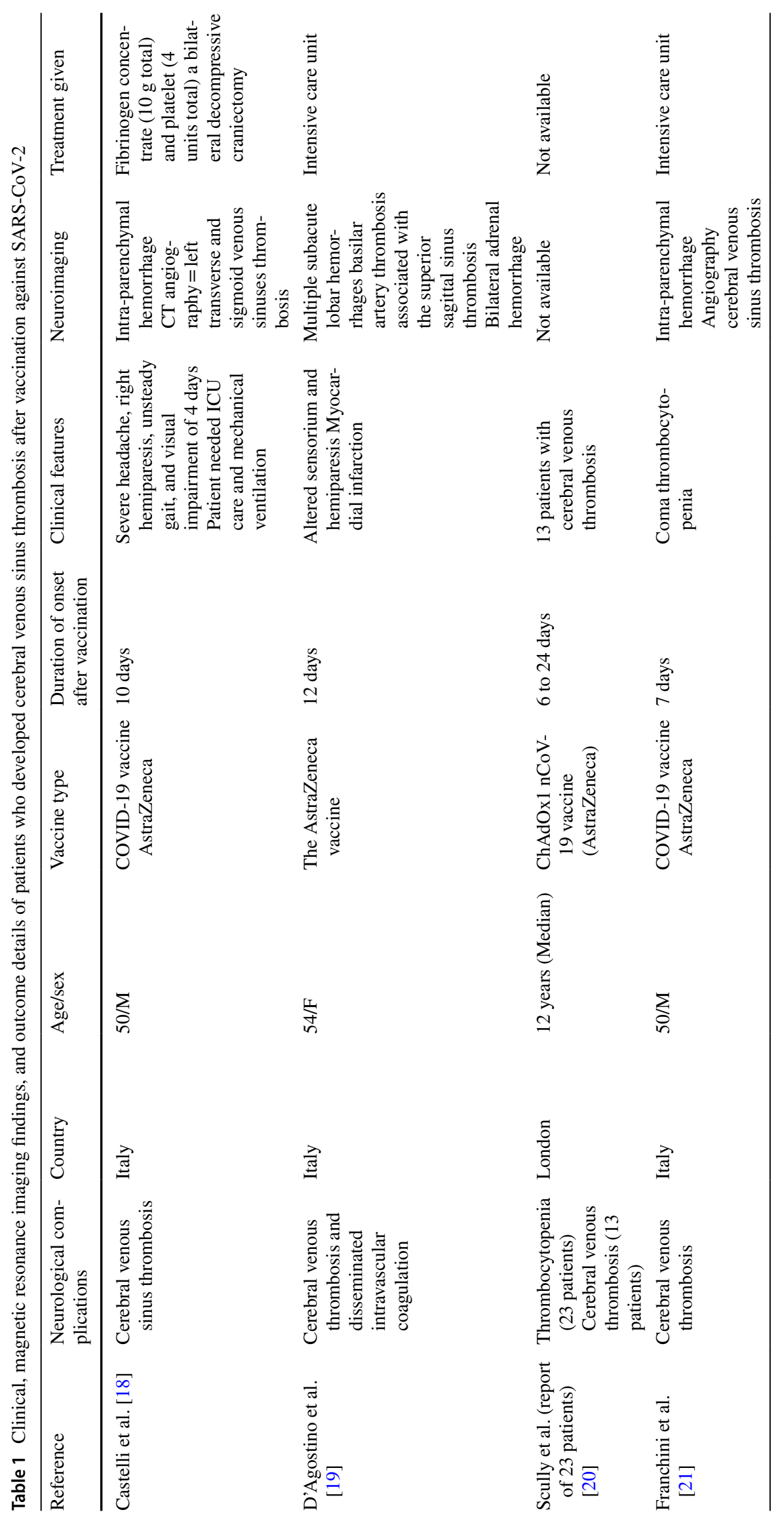




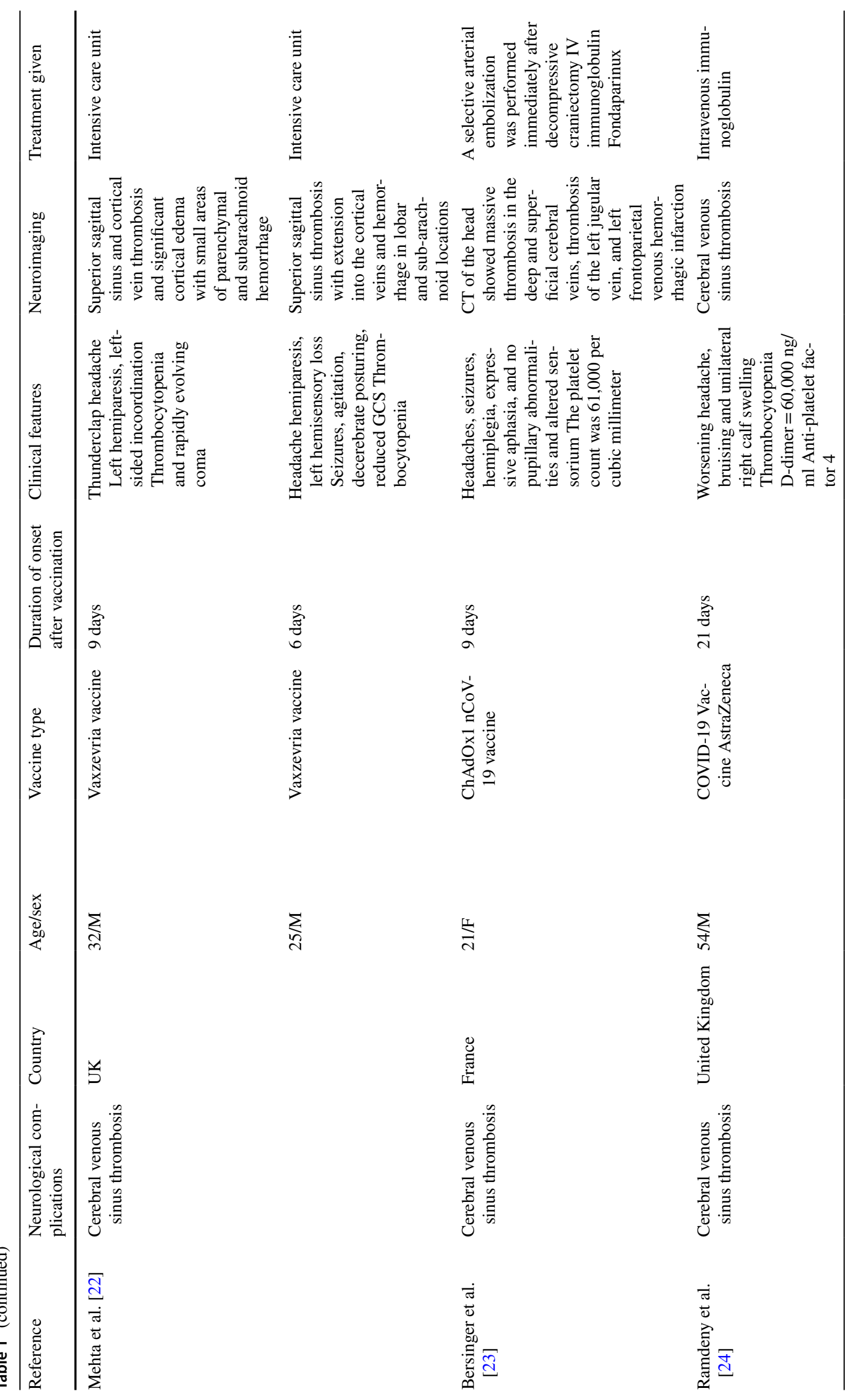




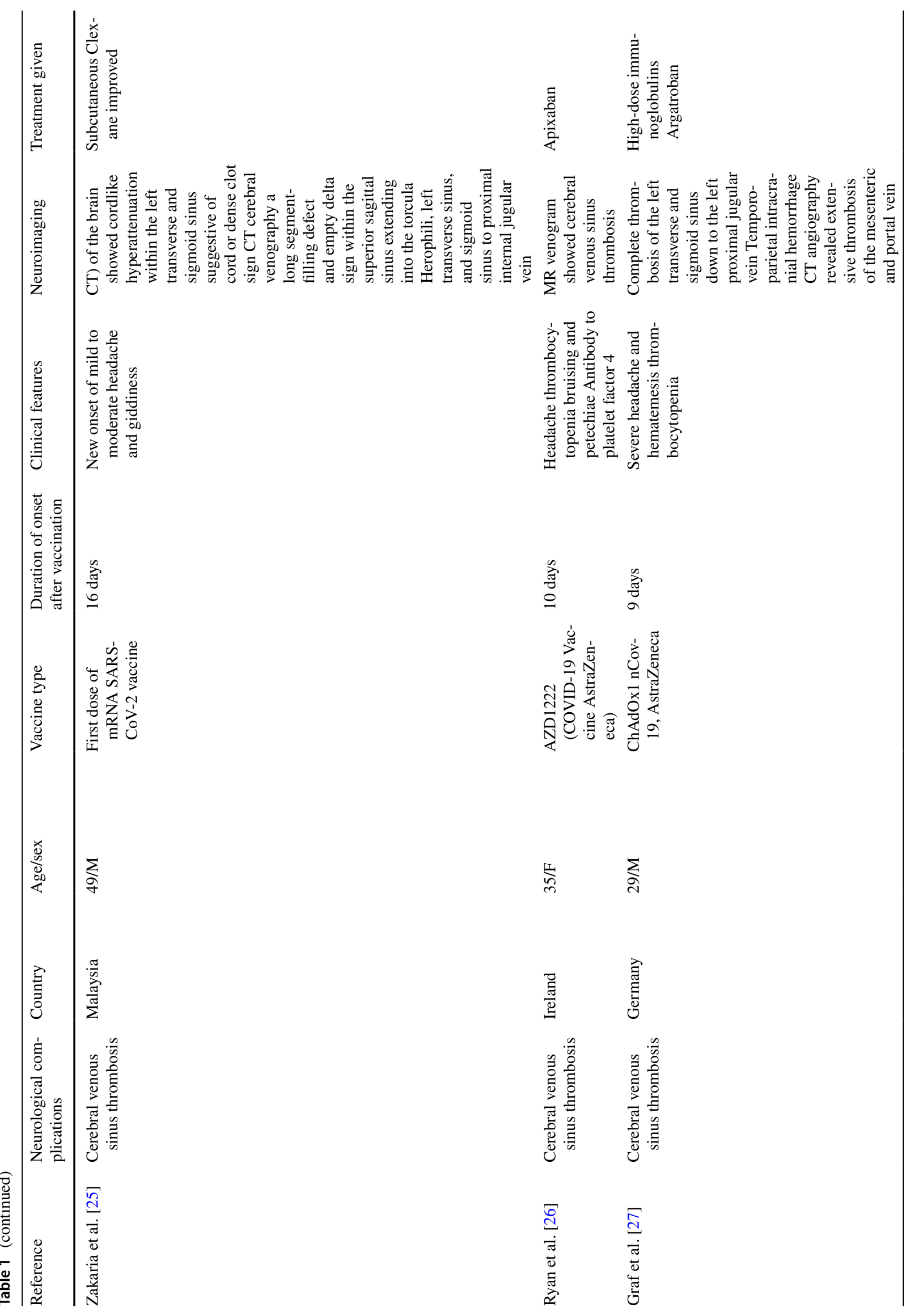




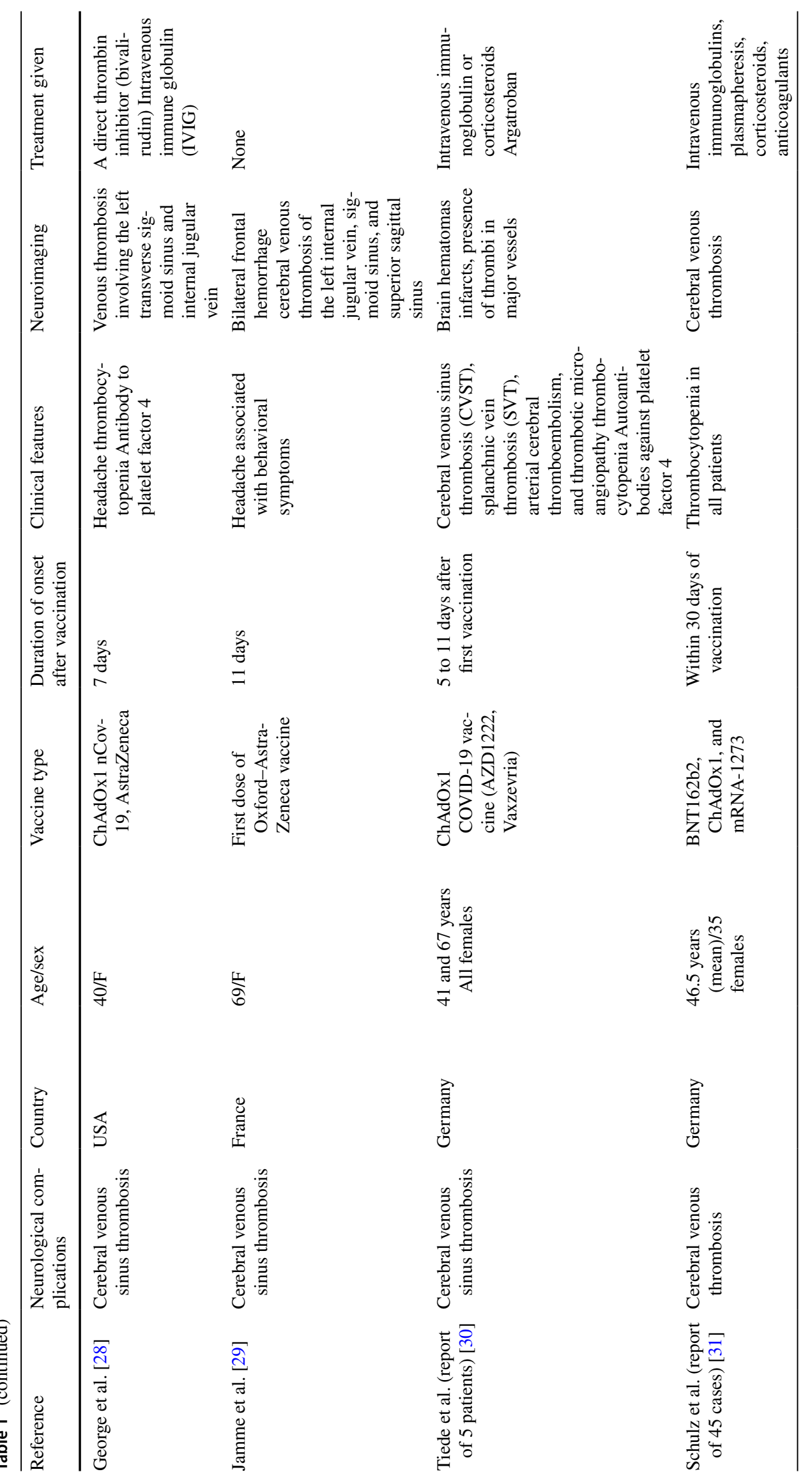




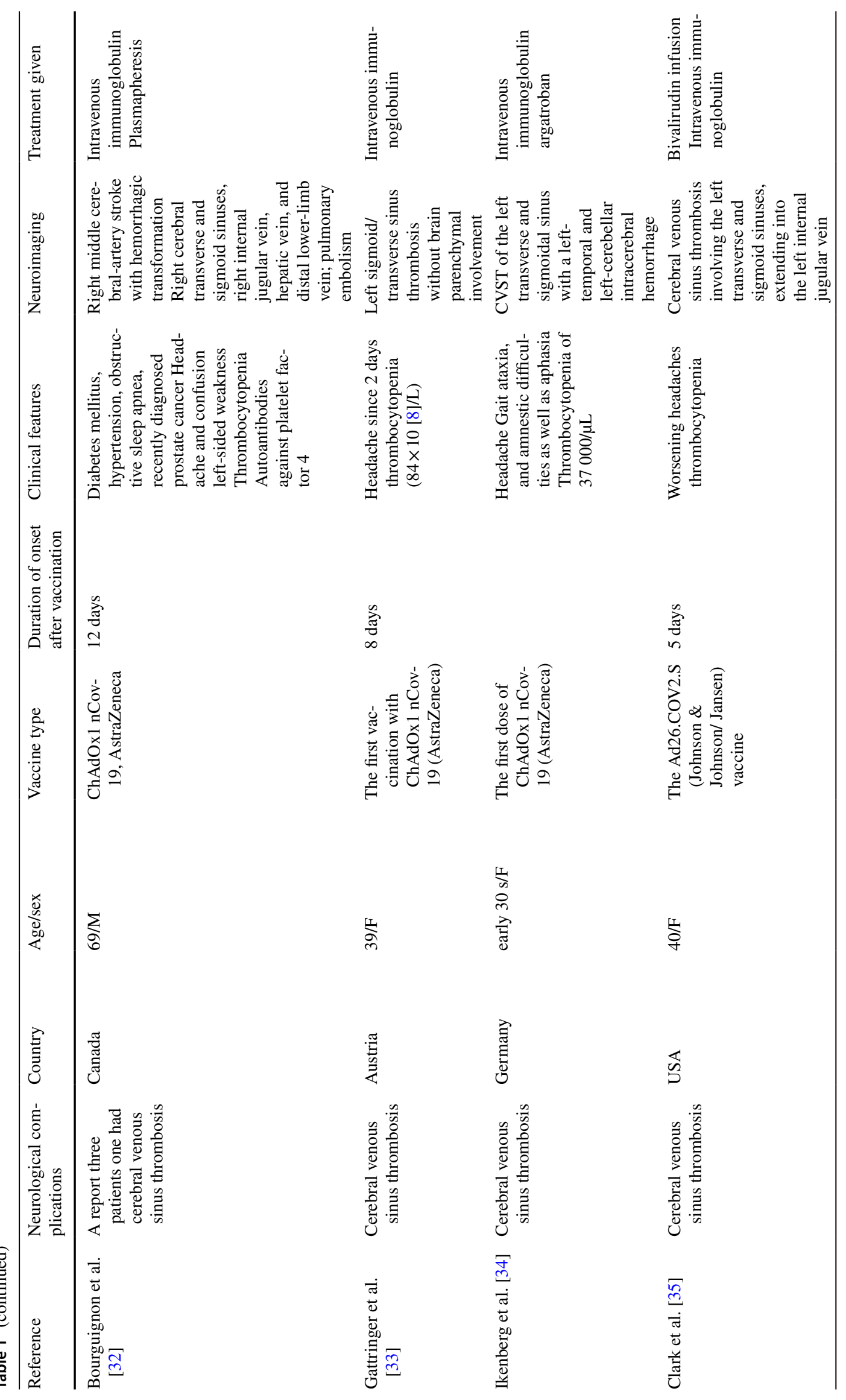




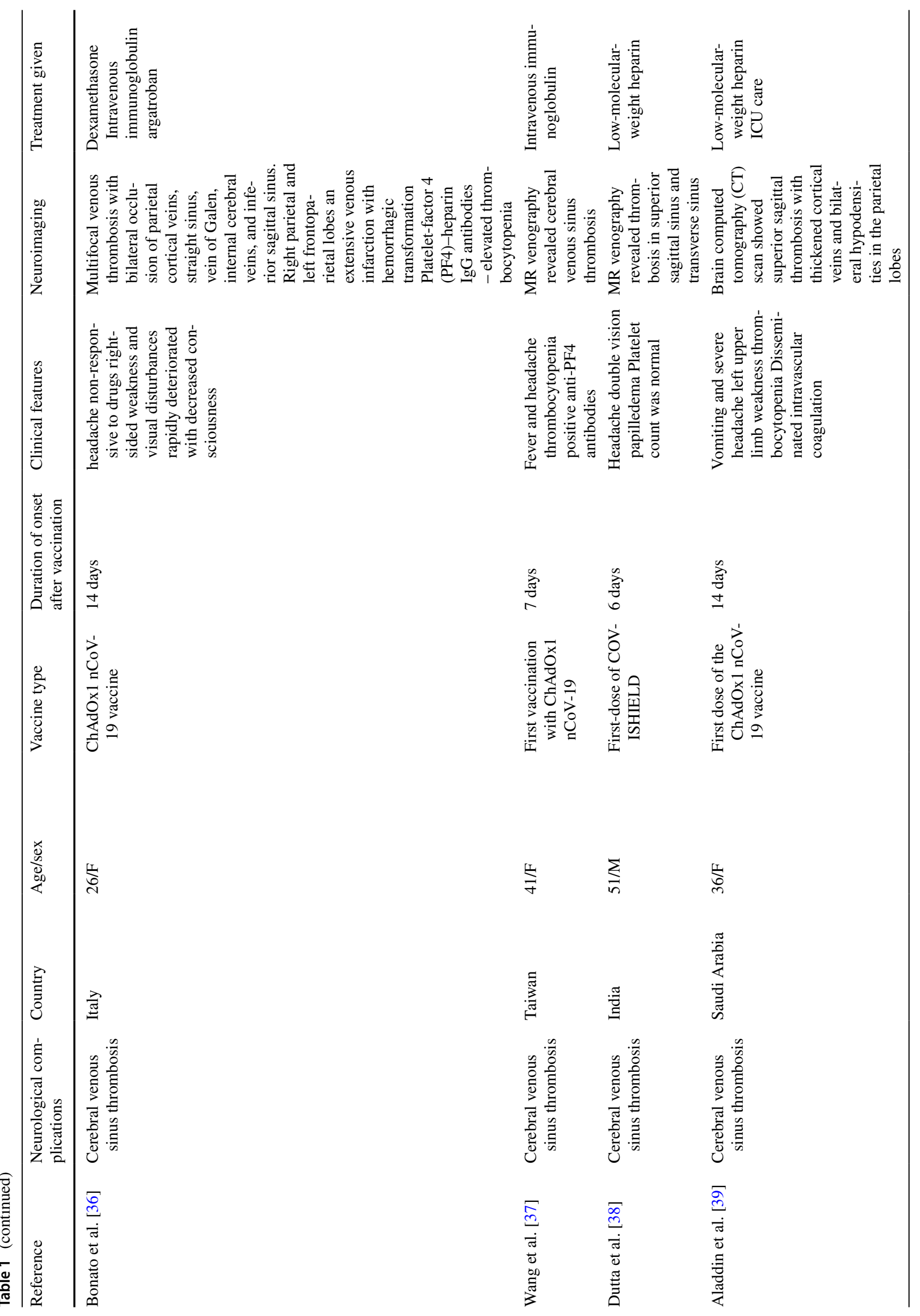




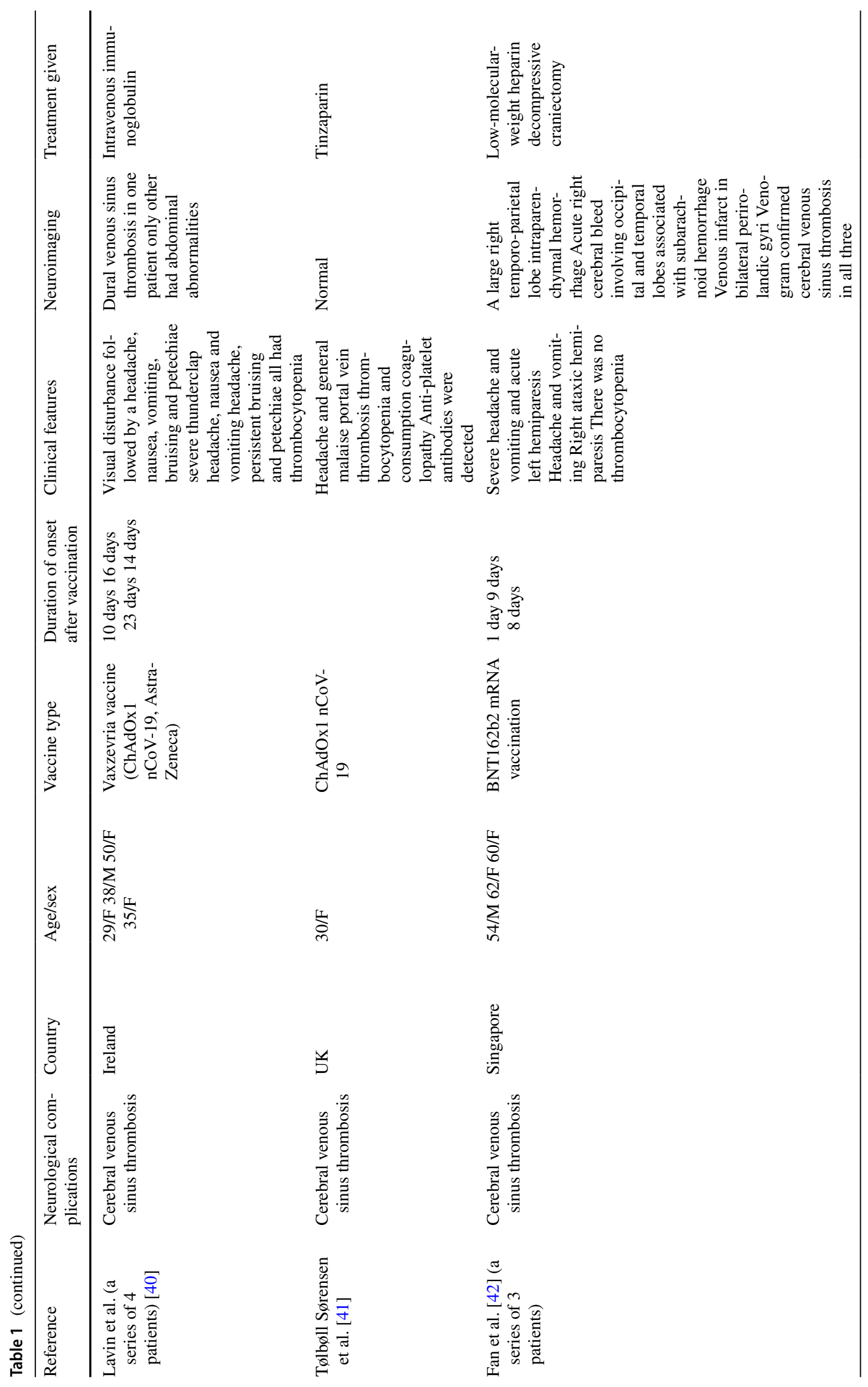




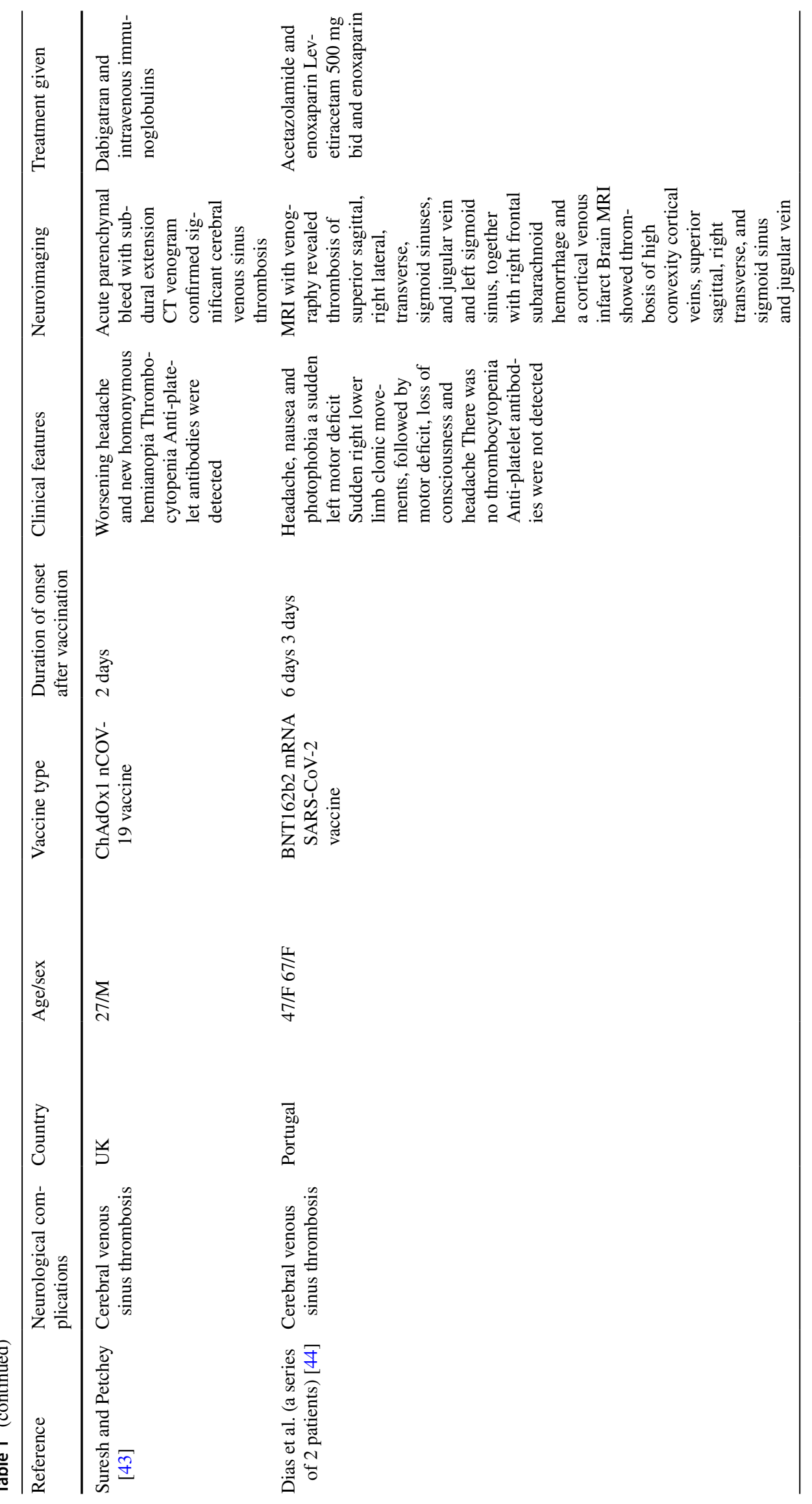




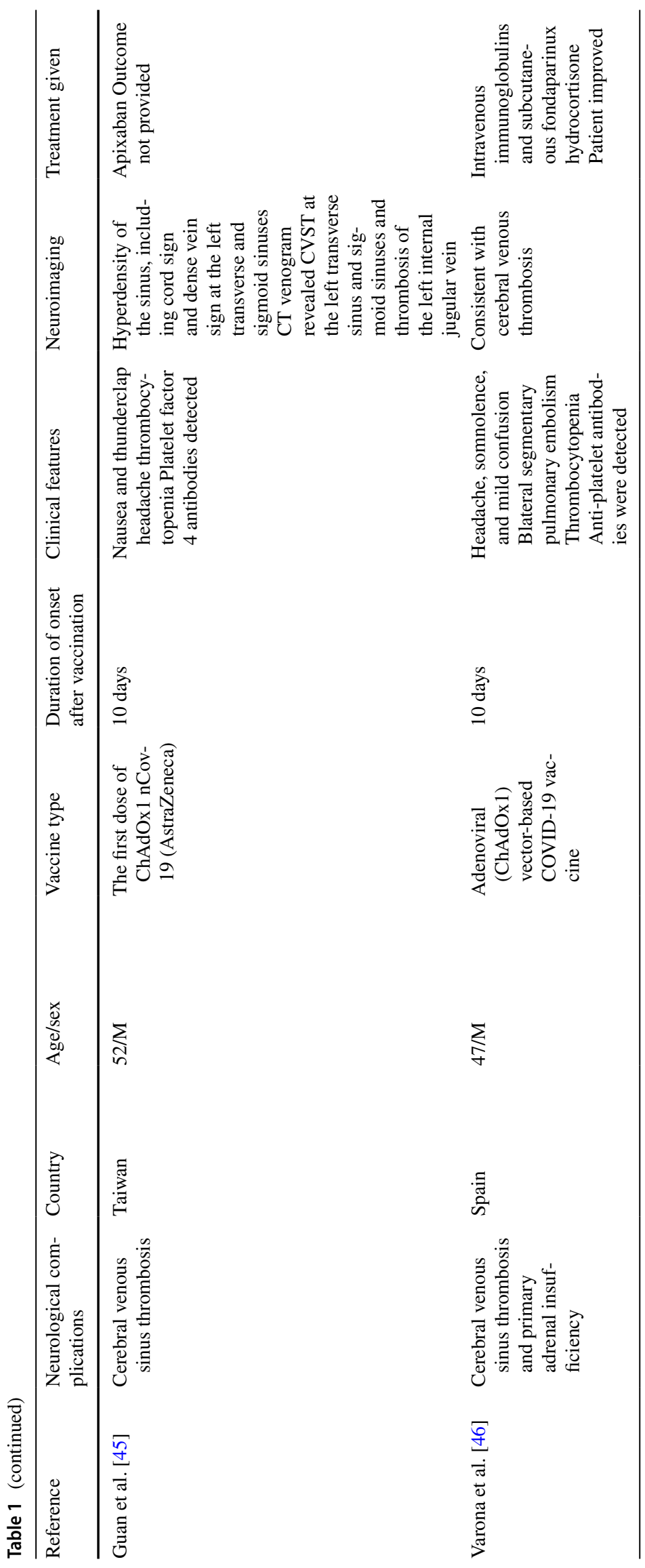




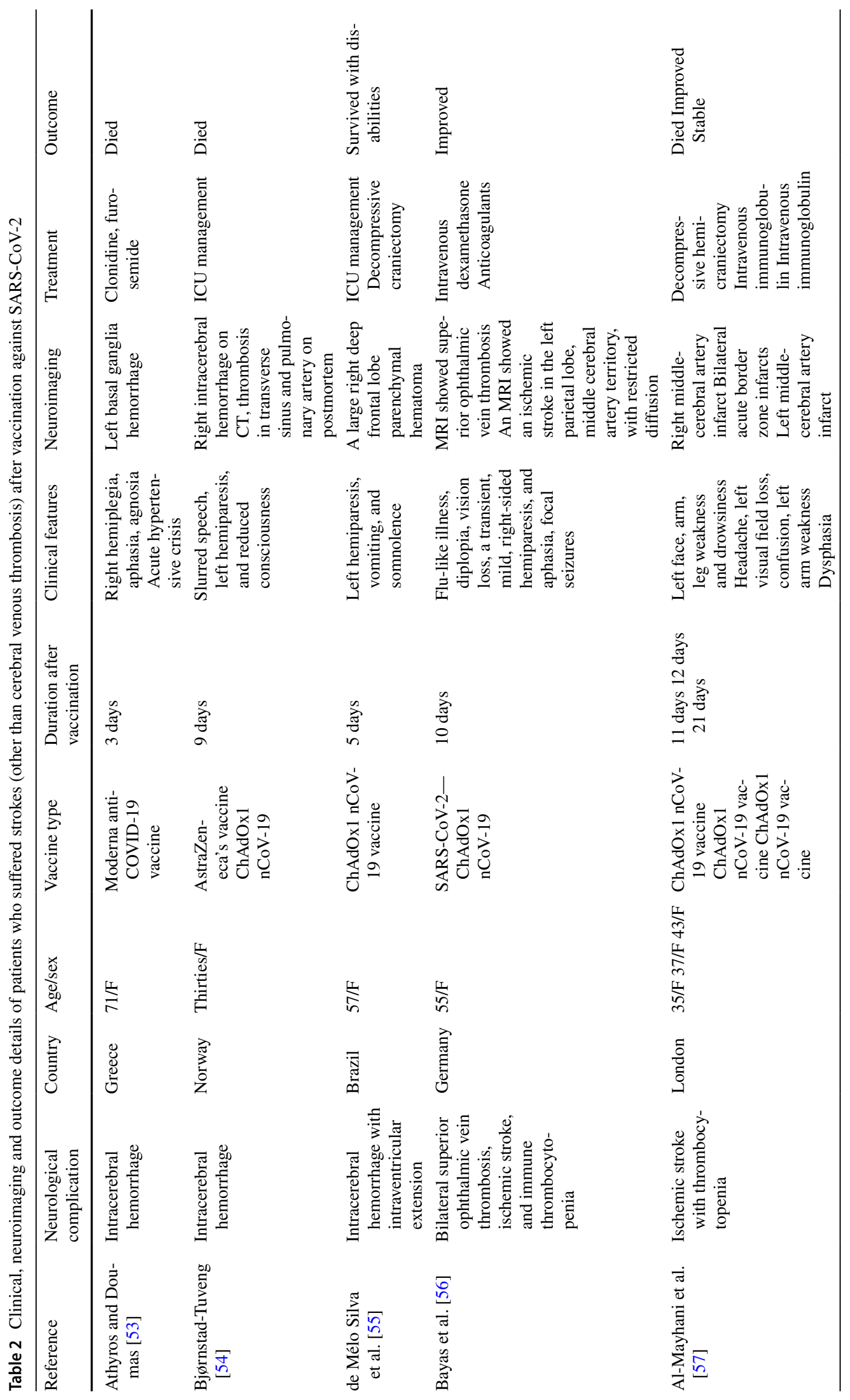




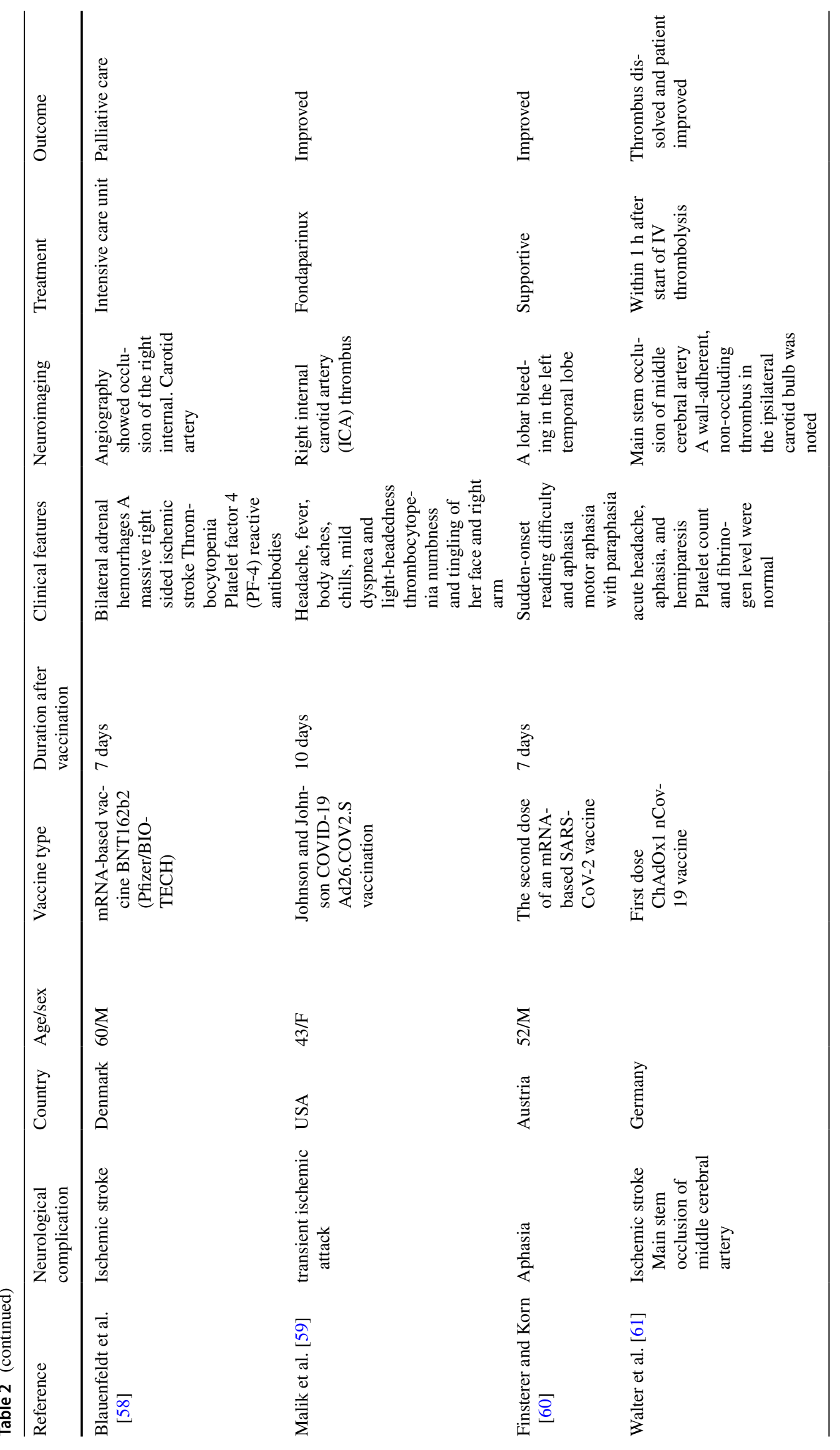


On the third post-vaccination day, the patient developed right hemiplegia, aphasia, and agnosia along with accelerated hypertension. Computed tomography revealed a hematoma in the left basal ganglia. On the 9th day, she died [53].

In another report, Bjørnstad-Tuveng et al. described a young woman, who had a fatal cerebral event following vaccination with AstraZeneca's ChAdOx1 nCoV-19 vaccine. She was found to have severe thrombocytopenia. The patient died the next day of the event. Post-mortem examination revealed antibodies against platelet factor 4 and the presence of small thrombi in the transverse sinus, frontal lobe, and pulmonary artery [54].

\section{Acute ischemic stroke}

Bayas and co-workers described a case that presented with superior ophthalmic vein thrombosis, ischemic stroke, and immune thrombocytopenia, after administration of viral vector-based vaccine. Intravenous dexamethasone resulted in marked improvement in platelet count [56]. Al-Mayhani et al. described three cases of vaccine-induced thrombotic thrombocytopenia, all presented with arterial strokes. Authors opined that young patients with arterial stroke after receiving the COVID-19 vaccine should always be evaluated for vaccine-induced thrombotic thrombocytopenia. Other laboratory tests, like platelet count, D-dimers, fibrinogen level, and testing for platelet factor 4 antibodies, should also be performed [57].

Blauenfeldt et al. described a 60-year-old woman, who presented with intractable abdominal pain, 7 days after receiving the adenoviral (ChAdOx1) vector-based COVID19 vaccine. Abdominal computed tomography revealed bilateral adrenal necrosis. Later, a massive right cerebral infarction, secondary to occlusion of the right internal carotid artery, occurred that led to death of the patient. Blood tests showed thrombocytopenia, elevated in D-dimer and platelet factor 4 antibodies [58].

Many reports of acute brain disorders like encephalopathy, seizures, acute disseminated encephalopathy, neuroleptic malignant syndrome, and post-vaccine encephalitis were described secondary to COVID-19 vaccine. These are summarized in Table 3 [62-75].

\section{Encephalopathy}

Some patients developed encephalopathy following administration of COVID-19 vaccines. Acute encephalopathy is defined as rapidly evolving disorder of the brain. Acute encephalopathy clinically manifests either with delirium, decreased consciousness, or coma.

\section{Delirium}

Delirium is characterized with fluctuating disturbance in attention and awareness. Zavala-Jonguitud and Pérez-García described an 89-year-old man, who developed delirium after mRNA vaccination. Within $24 \mathrm{~h}$, patient developed confusion, fluctuating attention, anxiety, and inversion of the sleep-wake cycle. Patient had many comorbidities (diabetes mellitus, hypertension, and chronic kidney disease). Patient improved after he was treated with quetiapine [68].

\section{Neuroleptic malignant syndrome}

Neuroleptic malignant syndrome is a life-threatening complication of many antipsychotic drugs characterized by fever, altered mental status, muscle rigidity, and autonomic dysfunction. In an isolated report, neuroleptic malignant syndrome, in a 74-year-old female with dementia and bipolar disorder 16 days after COVID-19 vaccination, has been described [69].

\section{Acute disseminated encephalomyelitis}

Acute disseminated encephalomyelitis (ADEM) is an acute inflammatory demyelinating disorder of the central nervous system. In the majority, ADEM is a post-infectious entity; in many cases, it even develops after vaccination [76]. In two cases, acute disseminated encephalomyelitis following COVID-19 vaccination has been reported. In first such case a 46-year-old woman received Sinovac inactivated SARS-CoV-2 vaccine before onset of clinical manifestations. Patient was presented with seizures, and magnetic resonance imaging revealed multiple, discrete T2/FLAIR periventricular. hyperintense lesions. Patient improved following methylprednisolone treatment [70] Another patient was a 24-year-old female who presented with encephalopathy along with limb weakness of 1-day duration. Two weeks prior, patient was vaccinated with inactivated SARS-CoV-2 vaccine. Magnetic resonance imaging revealed multiple, discrete T2/FLAIR hyperintense lesions in the brain. Patient improved following treatment with antiepileptics and intravenous immunoglobulins [71].

\section{Post-vaccinal encephalitis}

Zuhorn et al. reported a case series 3 patients, who presented with post-vaccinal encephalitis, akin to autoimmune encephalitis, 7 to 11 days after administration of adenovirus-based ChAdOx1 nCov-19 vaccine. All patients fulfilled the diagnostic criteria for possible autoimmune encephalitis. One interesting case had presented with opsoclonus-myoclonus syndrome. Two patients presented with cognitive decline, seizures, and gait disorder. 


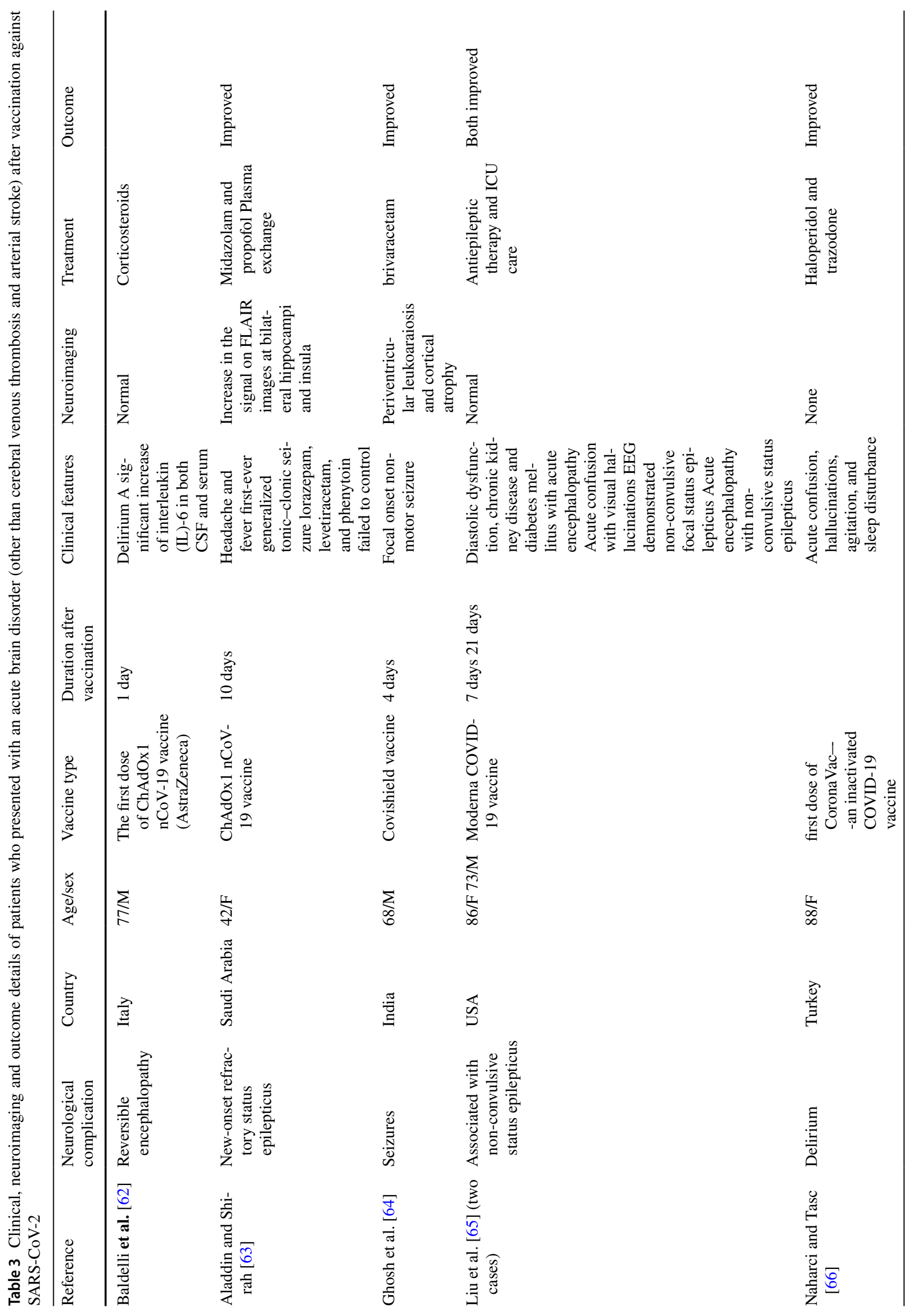




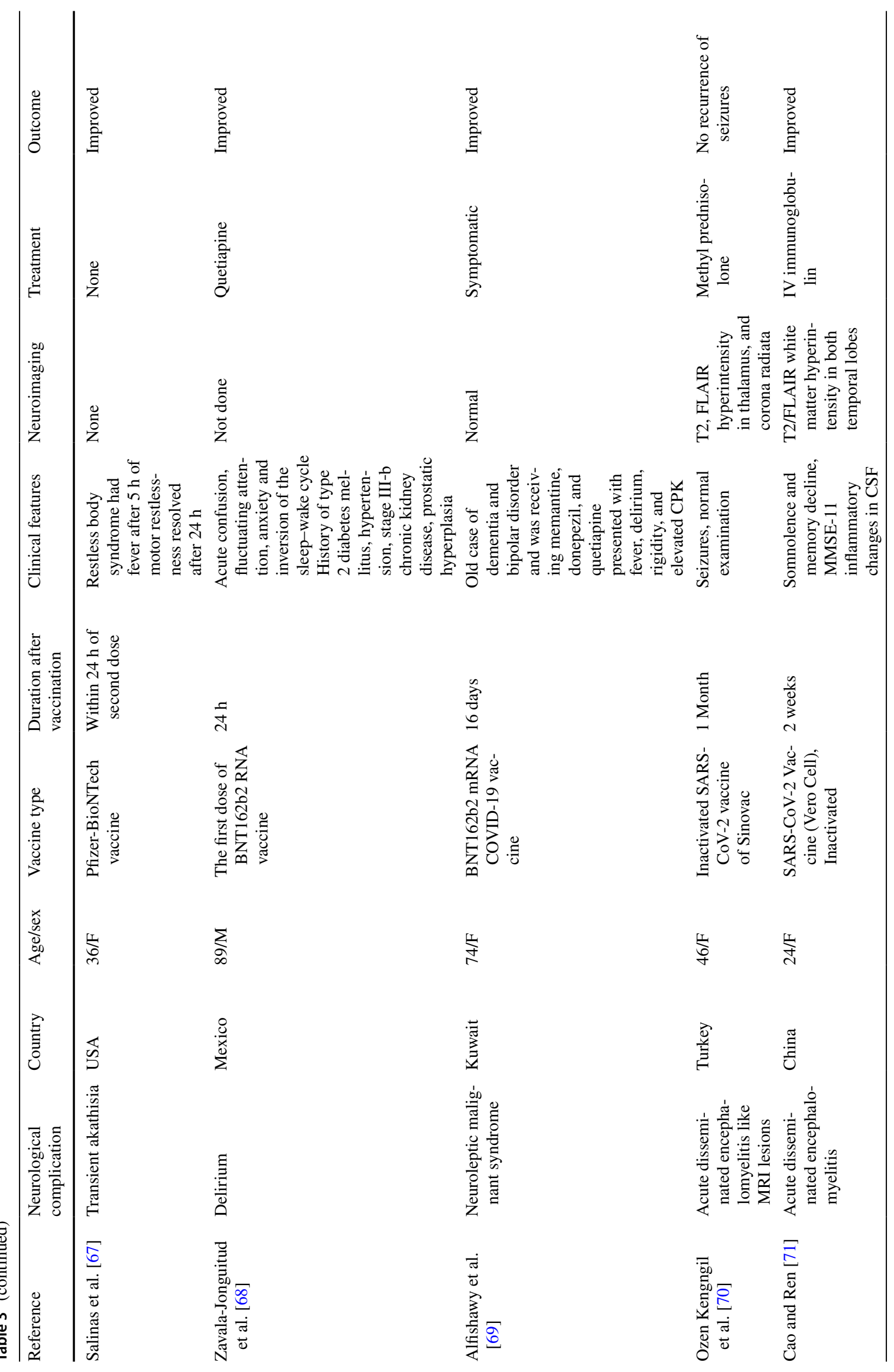




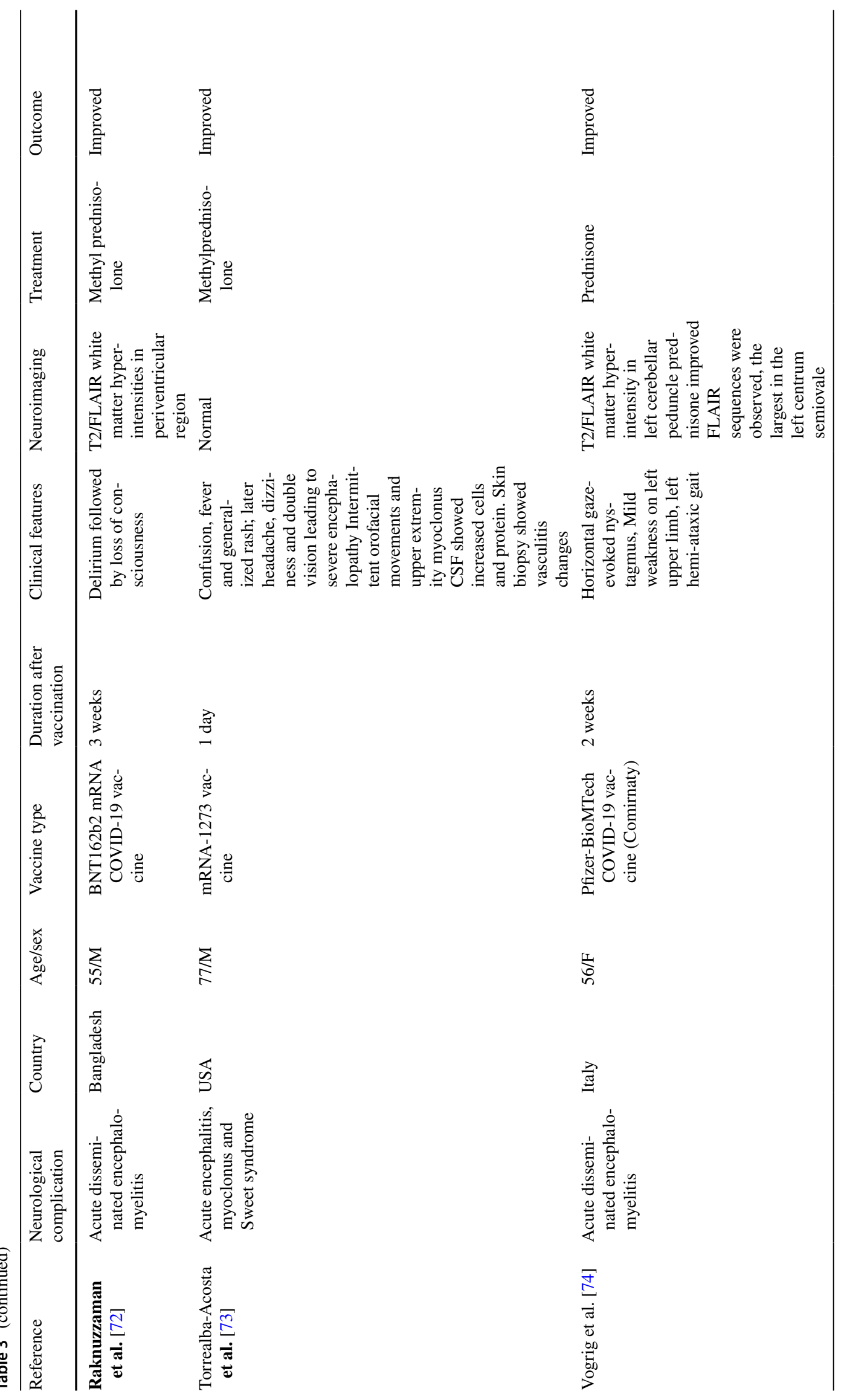




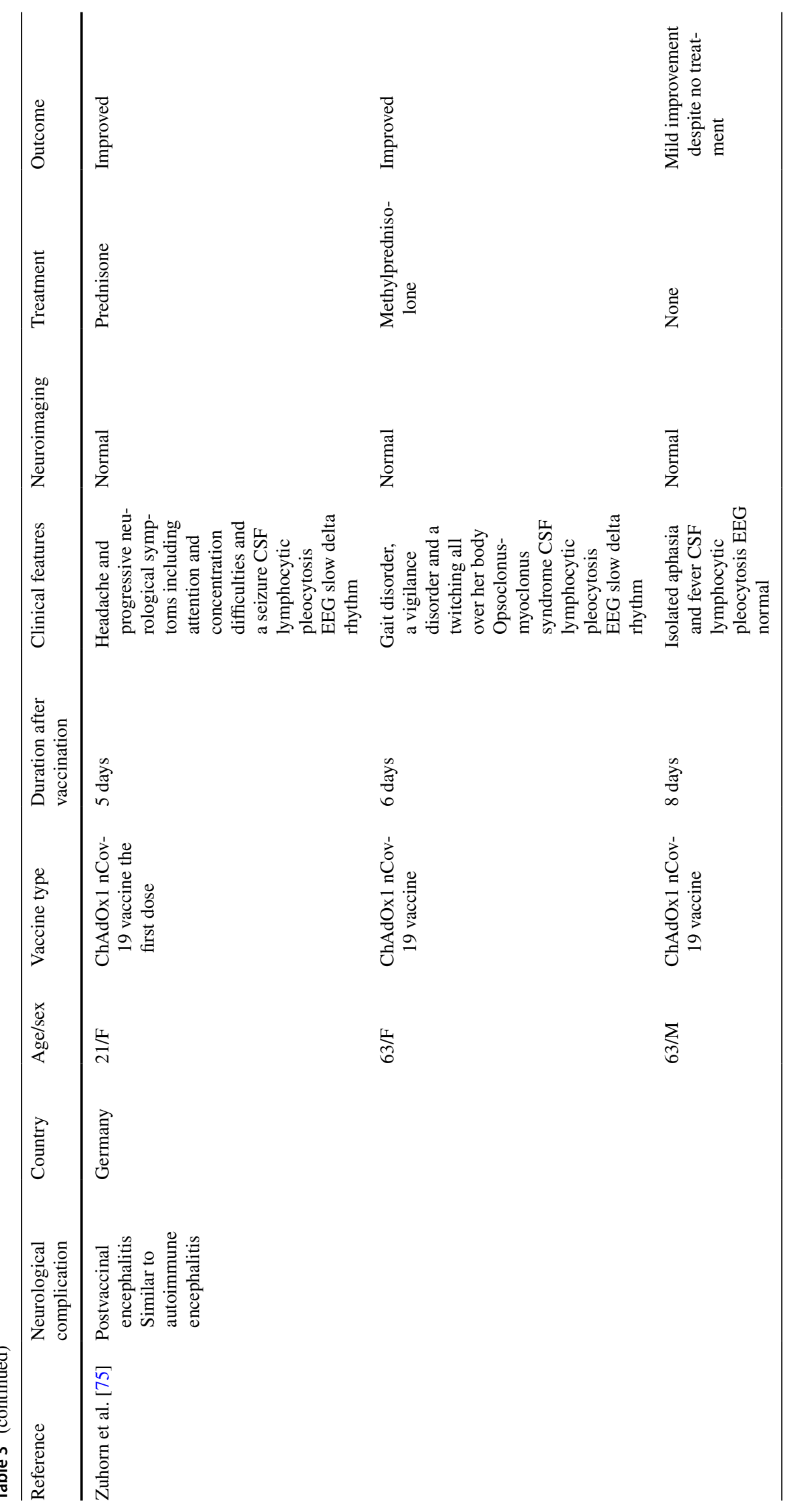


Neuroimaging did not reveal any abnormality. CSF pleocytosis was noted in all three patients. All patients responded well to corticosteroids [75].

\section{Transverse myelitis}

Acute transverse myelitis is an inflammatory spinal cord disorder that clinically manifests with the paraparesis/ quadriparesis, transverse sensory level, and bowel or bladder dysfunction. Acute transverse myelitis usually is a postinfectious disorder. Magnetic resonance imaging demonstrates T2/FLAIR hyperintensity extending several spinal cord segments. Autoimmunity via mechanism of molecular mimicry is usually responsible for spinal cord dysfunction. Adenoviral vector-based COVID-19 vaccines are more frequently associated with causation of transverse myelitis. In isolated cases, even inactivated virus vaccine and mRNA-based vaccines had precipitated acute demyelination spinal cord syndromes, like multiple sclerosis and neuromyelitis optica. Reports of myelitis associated with vaccination for SARS-CoV-2 are summarized in Table 4 [77-83].

Malhotra and colleagues reported a 36-year-old patient, who had short-segment myelitis 21 days after first dose of adenoviral vector-based (Oxford/AstraZeneca, COVISHIELD ${ }^{\mathrm{TM}}$ ) vaccine. Patient recovered completely after treatment with methylprednisolone [77]. Fitzsimmons and Nance reported another patient of acute transverse myelitis following Moderna vaccine (an mRNA vaccine). The 63-year-old patient developed symptoms of acute myelopathy within $24 \mathrm{~h}$ of vaccination. MRI revealed increased $\mathrm{T} 2$ cord signal seen in the distal spinal cord and conus. Patient improved considerably following treatment with methylprednisolone and intravenous immunoglobulin [78].

Earlier, in phase III trial of Oxford/AstraZeneca vaccine, 2 patients had developed transverse myelitis. One of the case of transverse myelitis was reported 14 days after booster vaccination. The expert committee considered that this case was the most likely an idiopathic, short segment transverse myelitis. The second case was reported 68 days post-vaccination. Experts believed that in this case, transverse myelitis was not likely to be associated with vaccination. This patient was earlier diagnosed as a case of multiple sclerosis $[84,85]$.

The pathogenesis of acute transverse myelitis following COVID-19 vaccination remains unknown. Possibly, SARSCoV-2 antigens present in the COVID-19 vaccine or its adenovirus adjuvant induce immunological reaction in the spinal cord. The occurrence of 3 reported acute transverse myelitis adverse effects among 11,636 participants in the vaccine trials was considered high and a cause of concern [86].

\section{Bell's palsy}

Several cases of Bell's palsy have occurred following COVID-19 vaccination. (Table 5) [87-95]. The instances of Bell's palsy are most often associated with mRNA vaccines [96]. Vaccine-associated Bell's palsy generally responds very well to the oral corticosteroids. The exact pathogenesis remains speculative.

In a case-control study, Shemer et al. compared clinical parameters of patients with Bell's palsy following mRNA vaccination with that of patients with Bell's palsy without vaccination. Out of 37 patients, 21 had received vaccination. Bell's palsy developed within 2 weeks following first dose of COVID-19 vaccination. There was no difference in any of the clinical parameter between vaccinated or unvaccinated groups [97].

Earlier, in the Pfizer-BioNTech clinical trial, which included 44,000 participants, 4 people had Bell's palsy. No case of Bell's palsy was reported in the placebo arm. In the Moderna trial, which included 30,400 participants, 3 vaccine recipients reported Bell's palsy. One person was in the placebo arm [98]. An article, published in the Lancet, analyzed the combined phase 3 data of Pfizer and Moderna trials and noted that the rate of Bell's palsy was higher than expected [98].

\section{Other cranial nerve involvement}

In isolated instances, mRNA vaccines were found associated with olfactory dysfunction and sixth cranial nerve palsy (Table 6) [99-104].

\section{Olfactory dysfunction}

Olfactory dysfunction is the most frequent neurological complication of COVID-19. Konstantinidis and colleagues reported two cases of smell impairment after second dose of the BioNTechBNT162b2 vaccine (Pfizer) administration [51].

Keir and colleagues reported phantosmia following administration of Pfizer COVID-19 vaccine. Patient complained of constantly "smelling smoke" and headaches. MRI of brain of the patient showed enhancement of the olfactory bulbs and bilateral olfactory tracts [100].

\section{Abducens nerve palsy}

Reyes-Capo et al. reported a 59-year-old lady, who presented with an abducen nerve palsy 2 days post-vaccination 


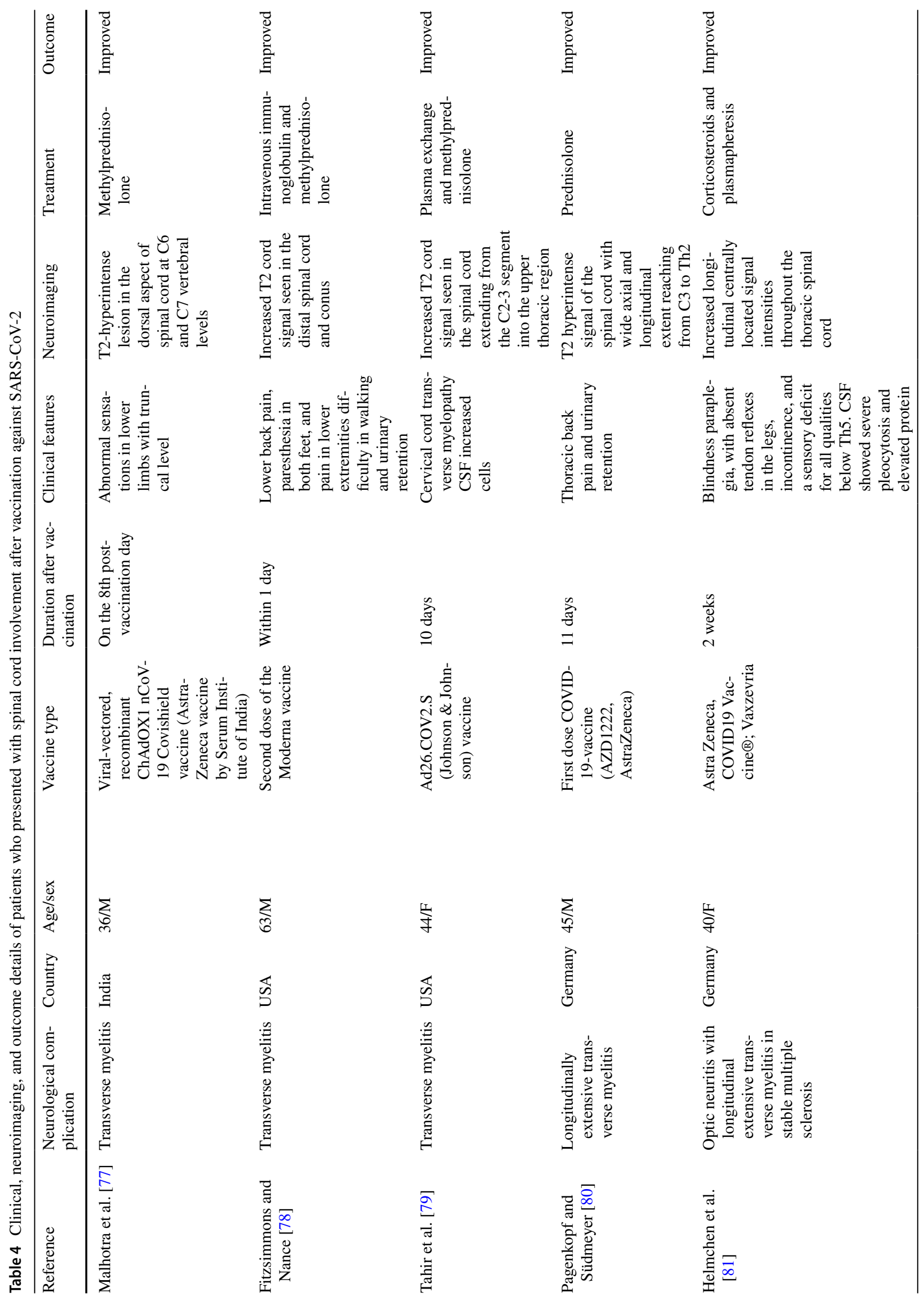




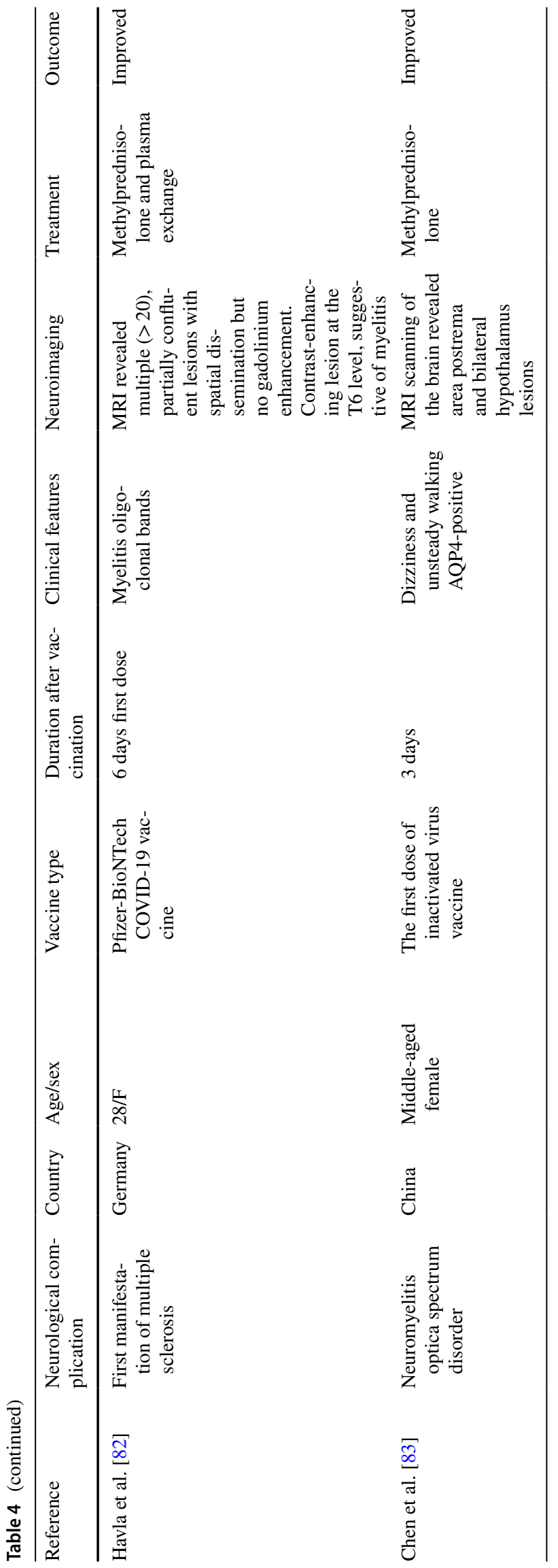

(Pfizer-BioNTech mRNA vaccine). Neuroimaging in this patient was normal..

\section{Otologic manifestations}

A variety of otologic manifestations has been noted following COVID-19 vaccination. Parrino and colleagues described three patients with sudden unilateral tinnitus following BNT162b2 mRNA vaccine administration. Tinnitus rapidly resolved in 2 cases. Wichova and colleagues in a retrospective review recorded 30 patients, who either had significantly exacerbated otologic symptoms or had a new symptom after getting mRNA vaccine. Post-vaccination otologic manifestations included hearing loss with tinnitus, dizziness, or with vertigo. In some patients, with Menière's disease or autoimmune inner ear disease, vaccine led to exacerbation of the pre-existing otologic symptoms $[102,105]$.

\section{Acute vision loss}

Santovito and Pinna reported an unusual patient, who developed acute visual impairment following the 2 nd dose of the Pfizer-BioNTech COVID-19 vaccine. Prior to visual symptoms, patient experienced unilateral headache. He also reported mild confusion, asthenia, and profound nausea. His symptoms got relieved after taking analgesics. Possibly, patient had an acute attack of migraine with aura that got precipitated by the vaccine [106].

\section{Guillain-Barré syndrome}

Guillain-Barré syndrome is a post-infectious disorder of peripheral nerve manifesting with lower motor neuron type of sensory-motor quadriparesis. Acute motor weakness is frequently preceded by an antecedent microbial infection. There are numerous reports indicating that COVID-19 infection can trigger Guillain-Barré syndrome. The US Food and Drug Administration has recently expressed its concern regarding a possible association between the Johnson and Johnson COVID-19 vaccine with Guillain-Barré syndrome [107].

After emergency use approvals, all kinds of COVID-19 vaccines were found associated with Guillain-Barré syndrome. Adenovector-based vaccines were more frequently associated with Guillain-Barré syndrome. Earlier, in phase 3 trial of Johnson and Johnson adenovirus vector-based COVID-19 vaccine, 2 patients developed Guillain-Barré syndrome. One patient belonged to vaccine group and other to placebo group. Both patients had Guillain-Barré syndrome within 2 weeks of receiving injections. The GuillainBarré syndrome in the vaccine arm was preceded by chills, nausea, diarrhea, and myalgia [108, 109]. 


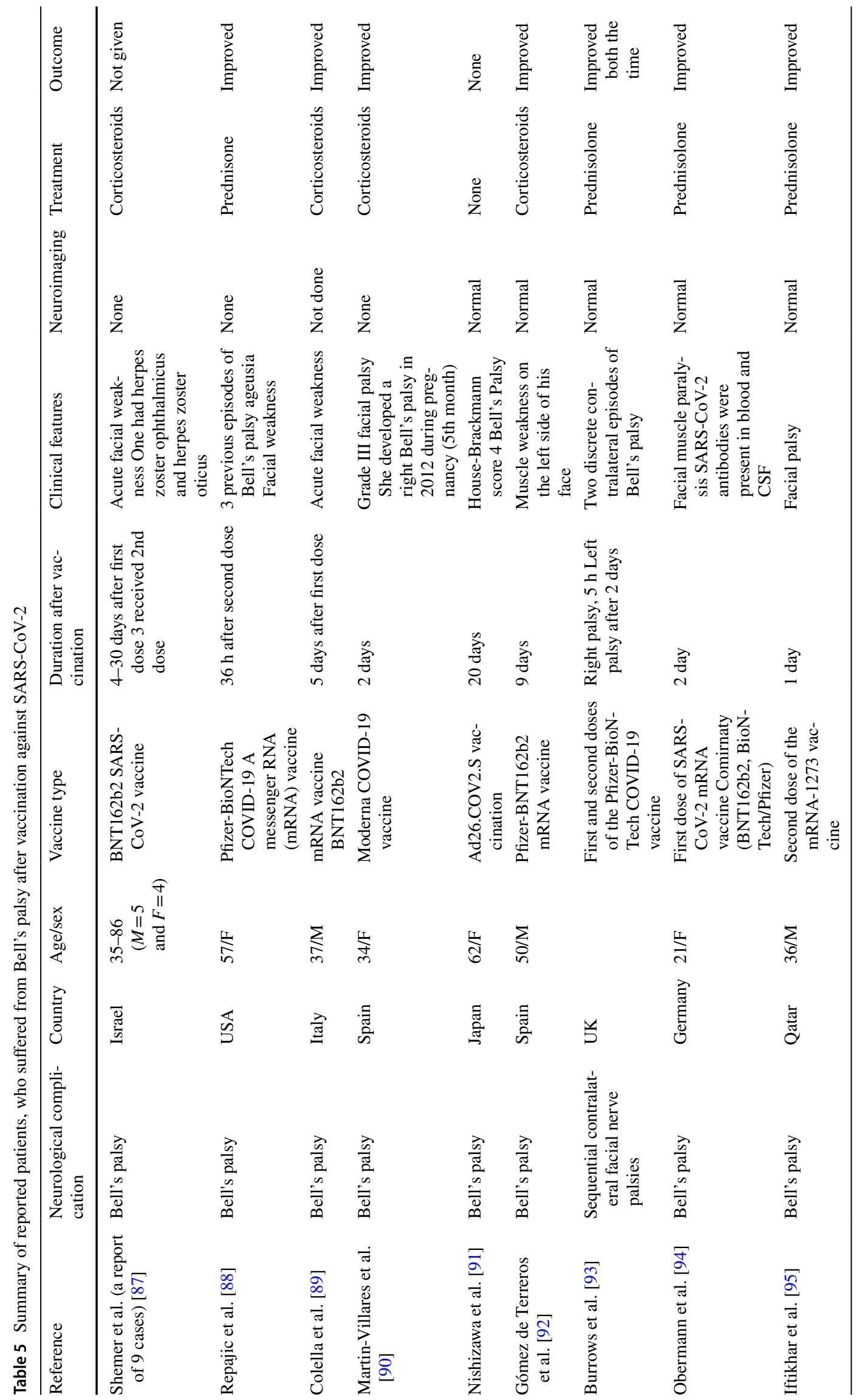




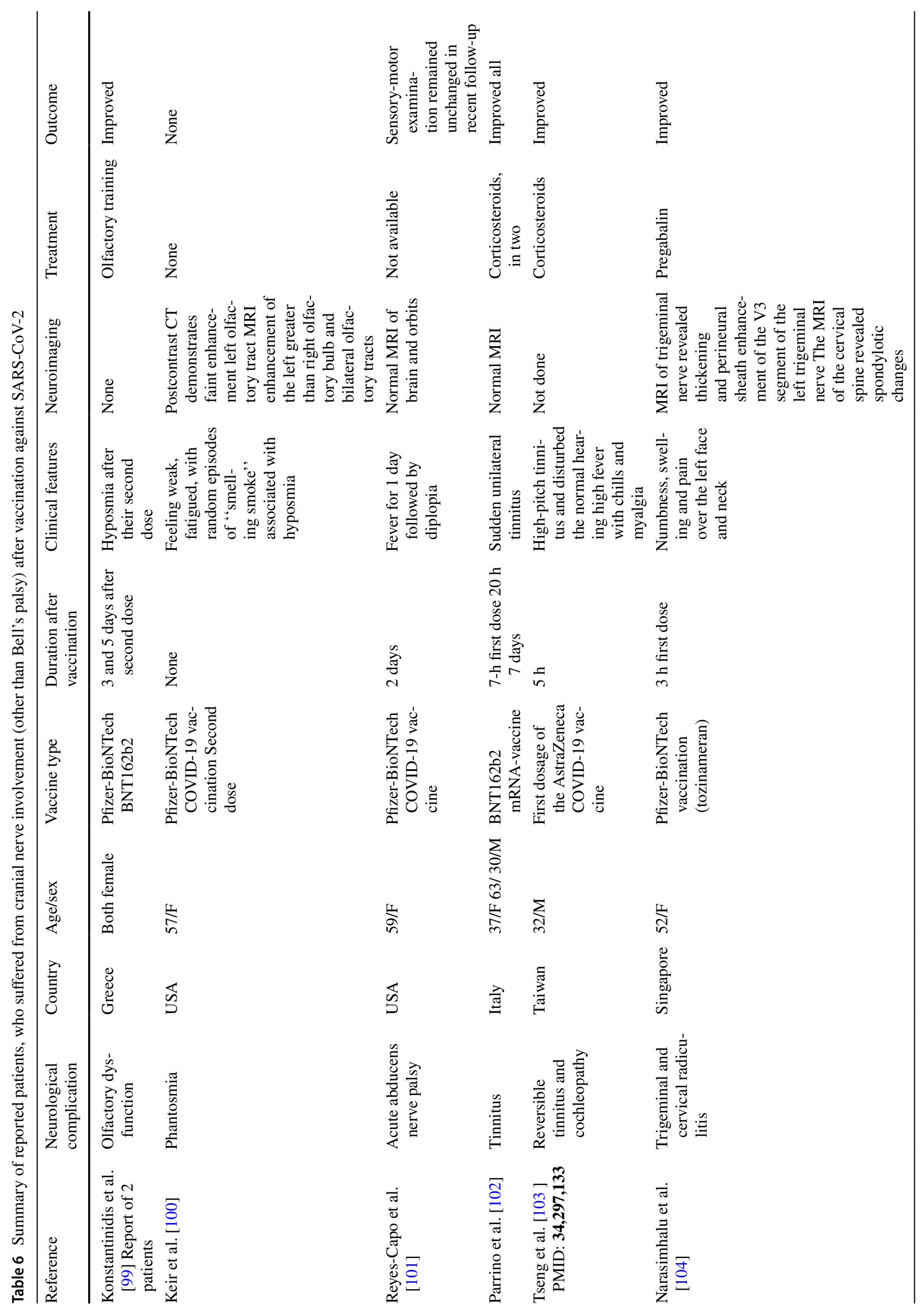




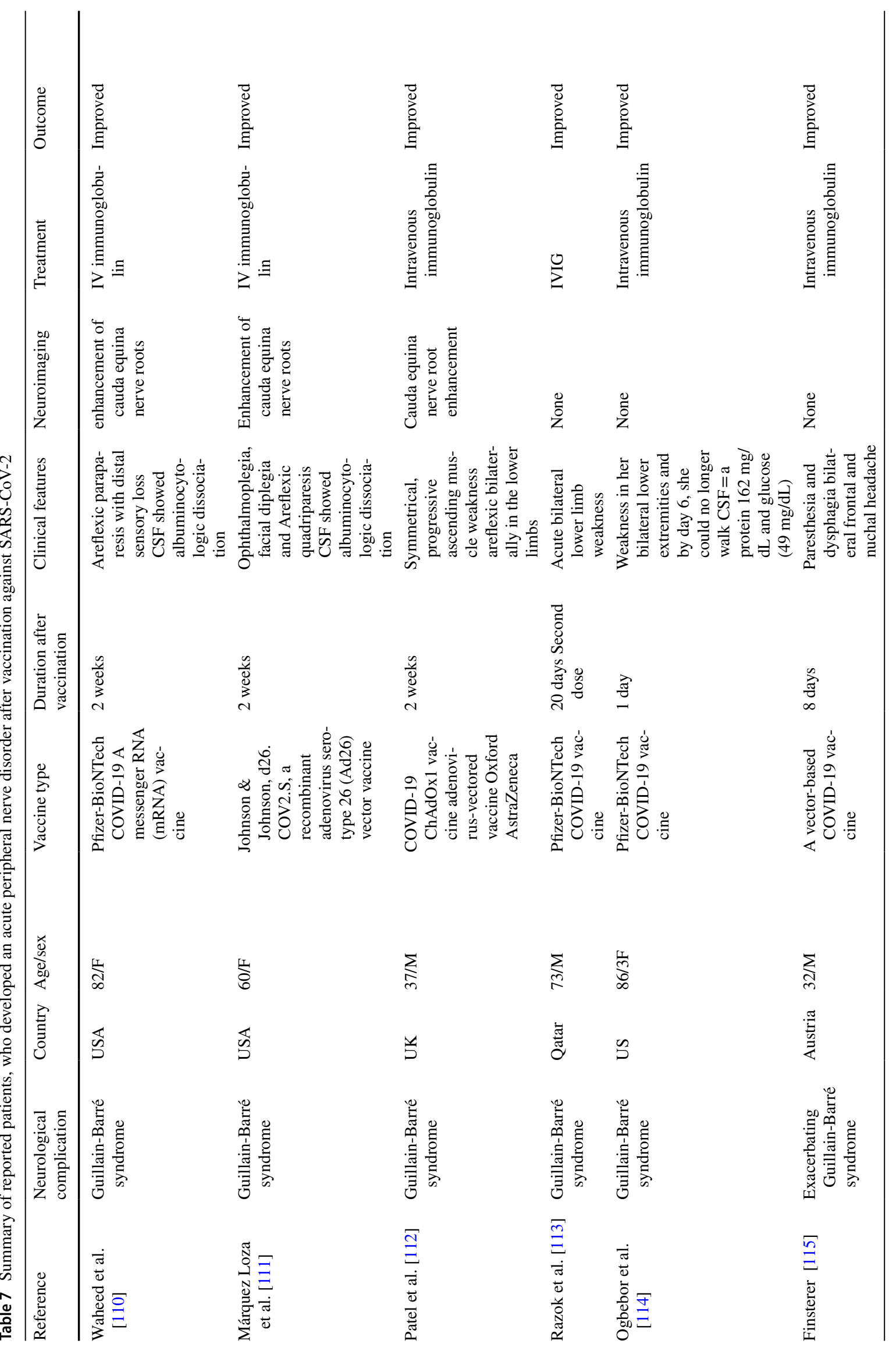




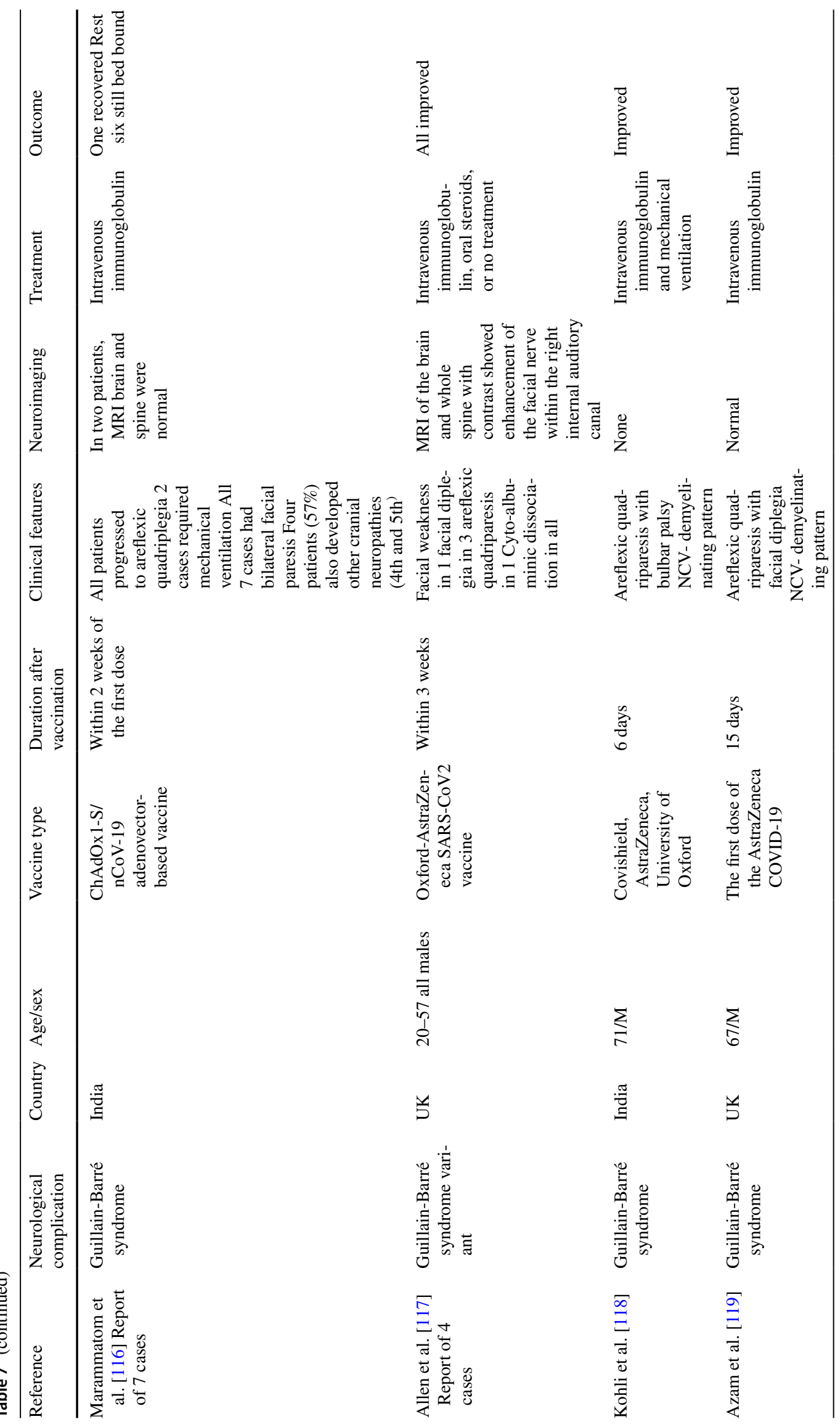




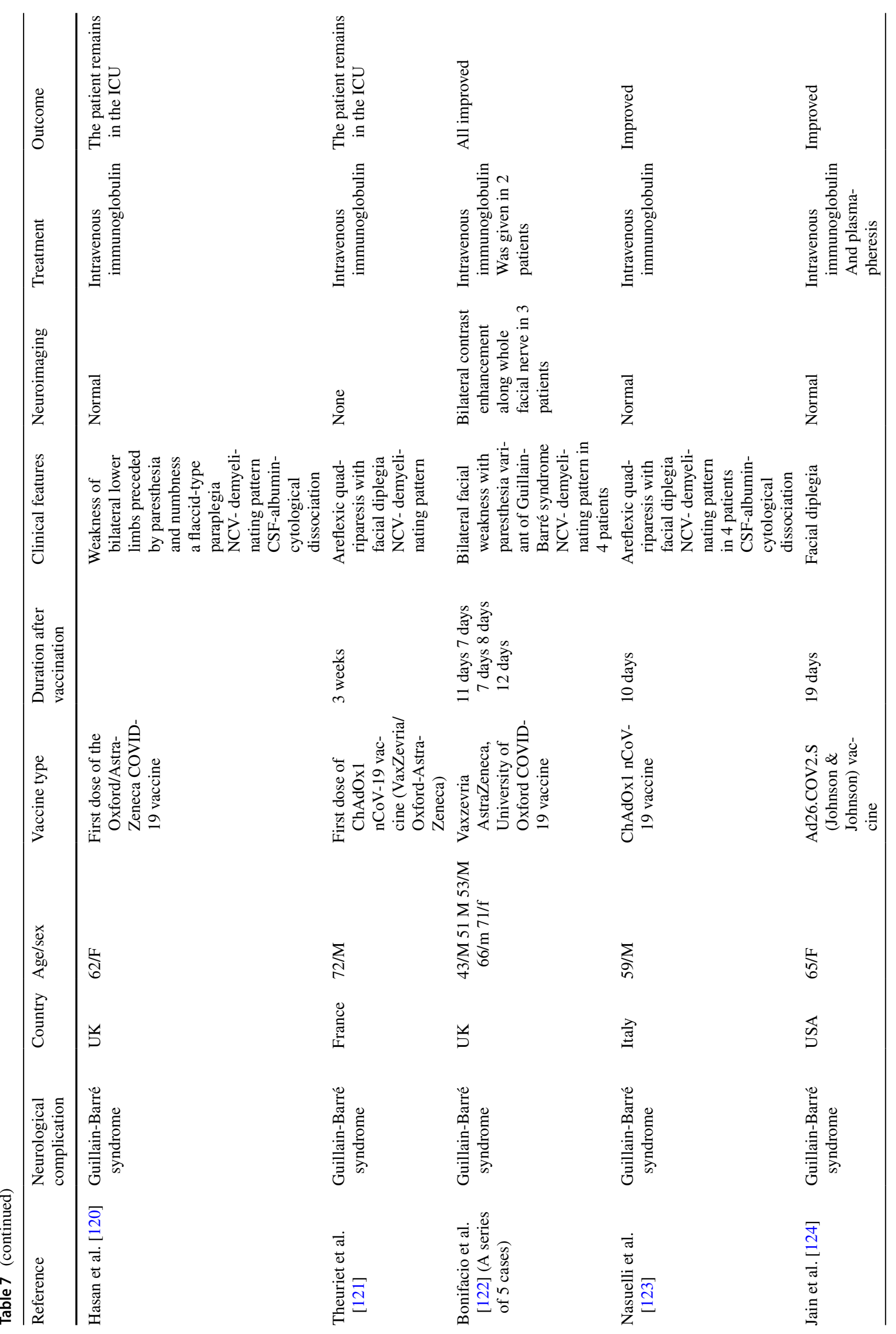




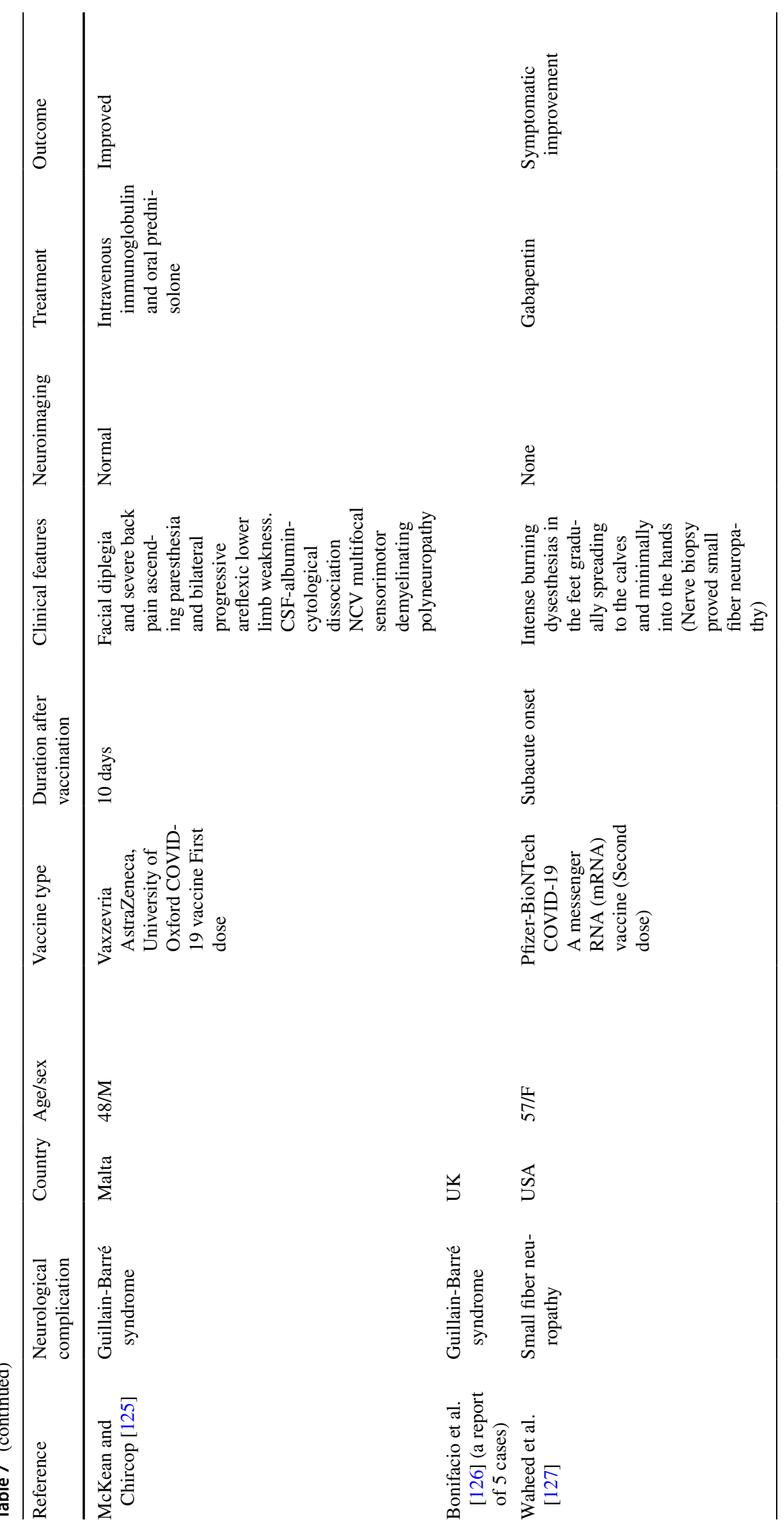




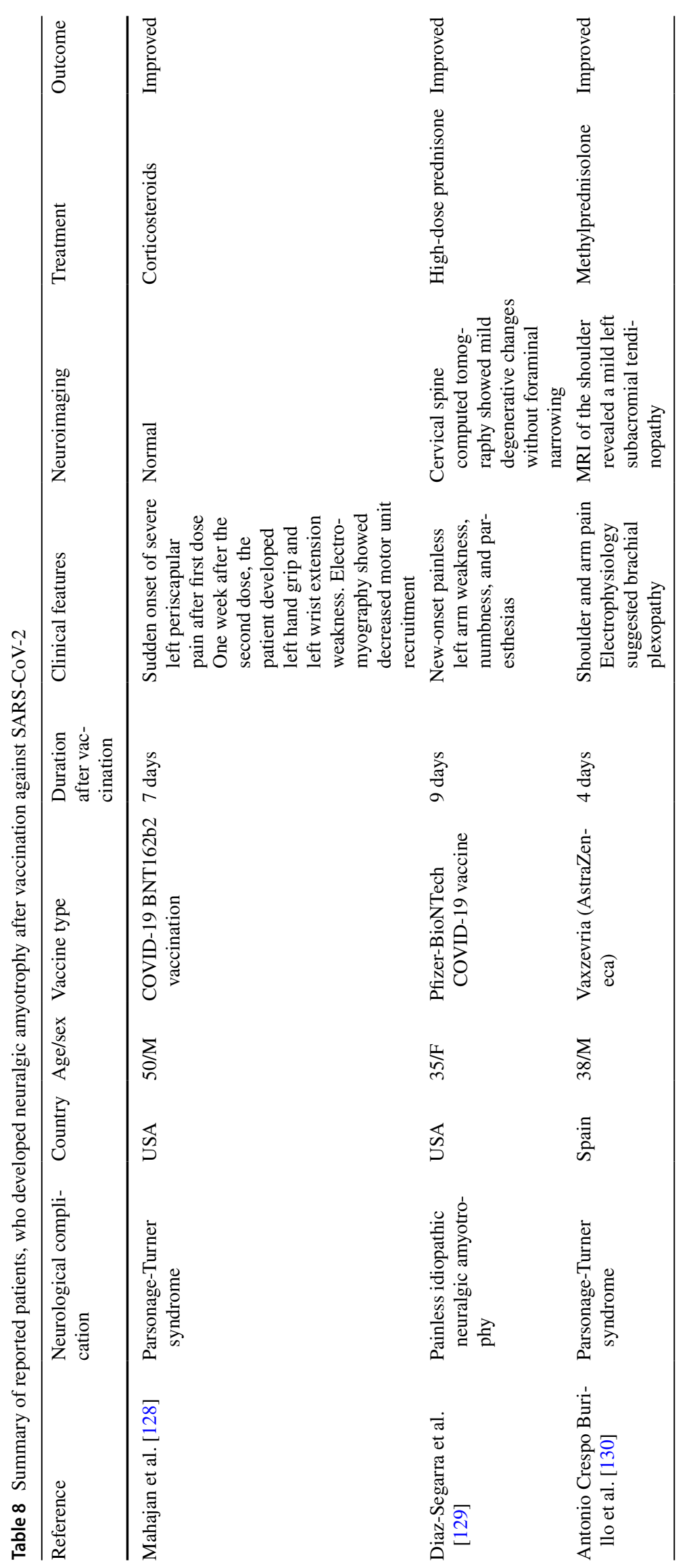




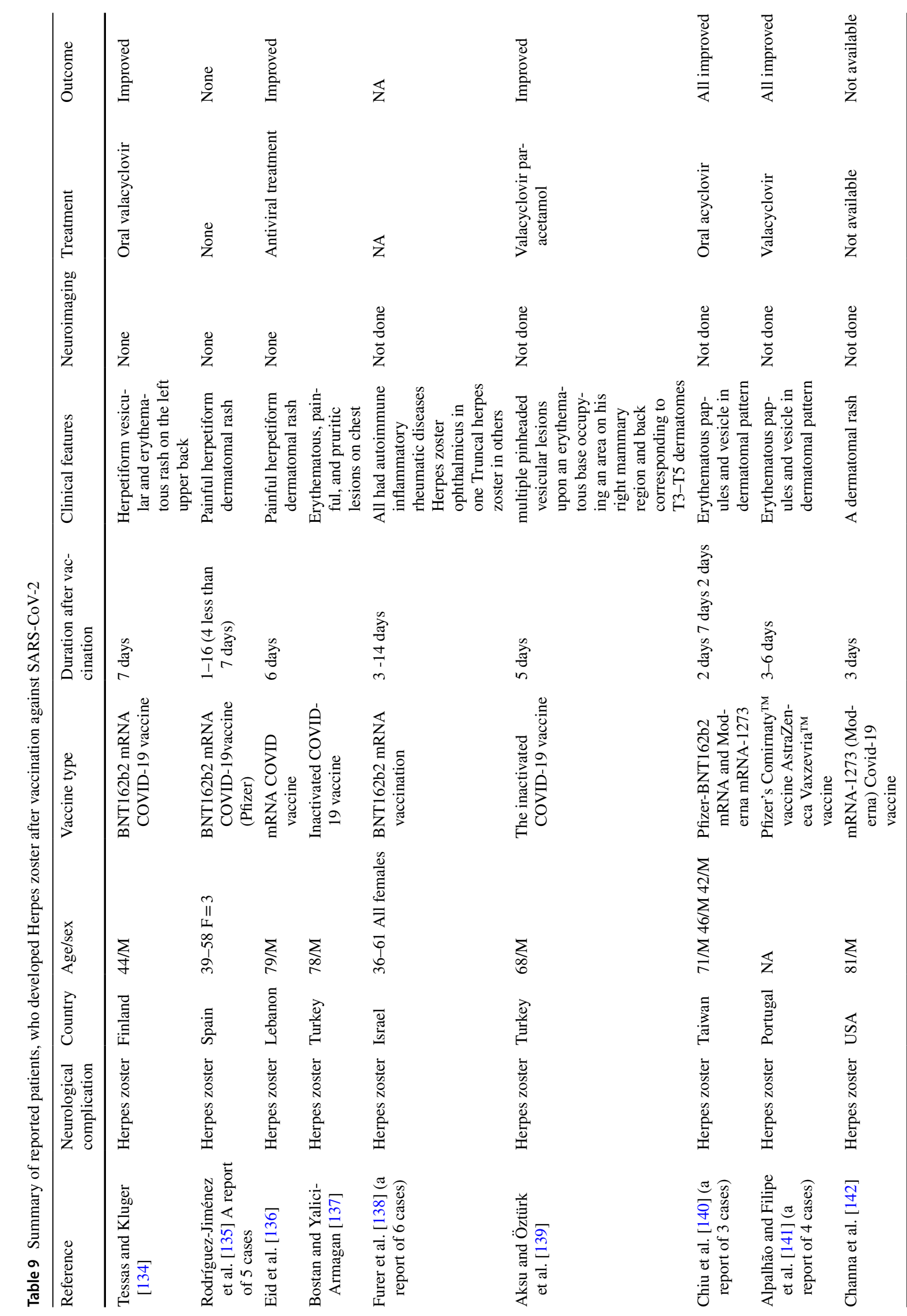




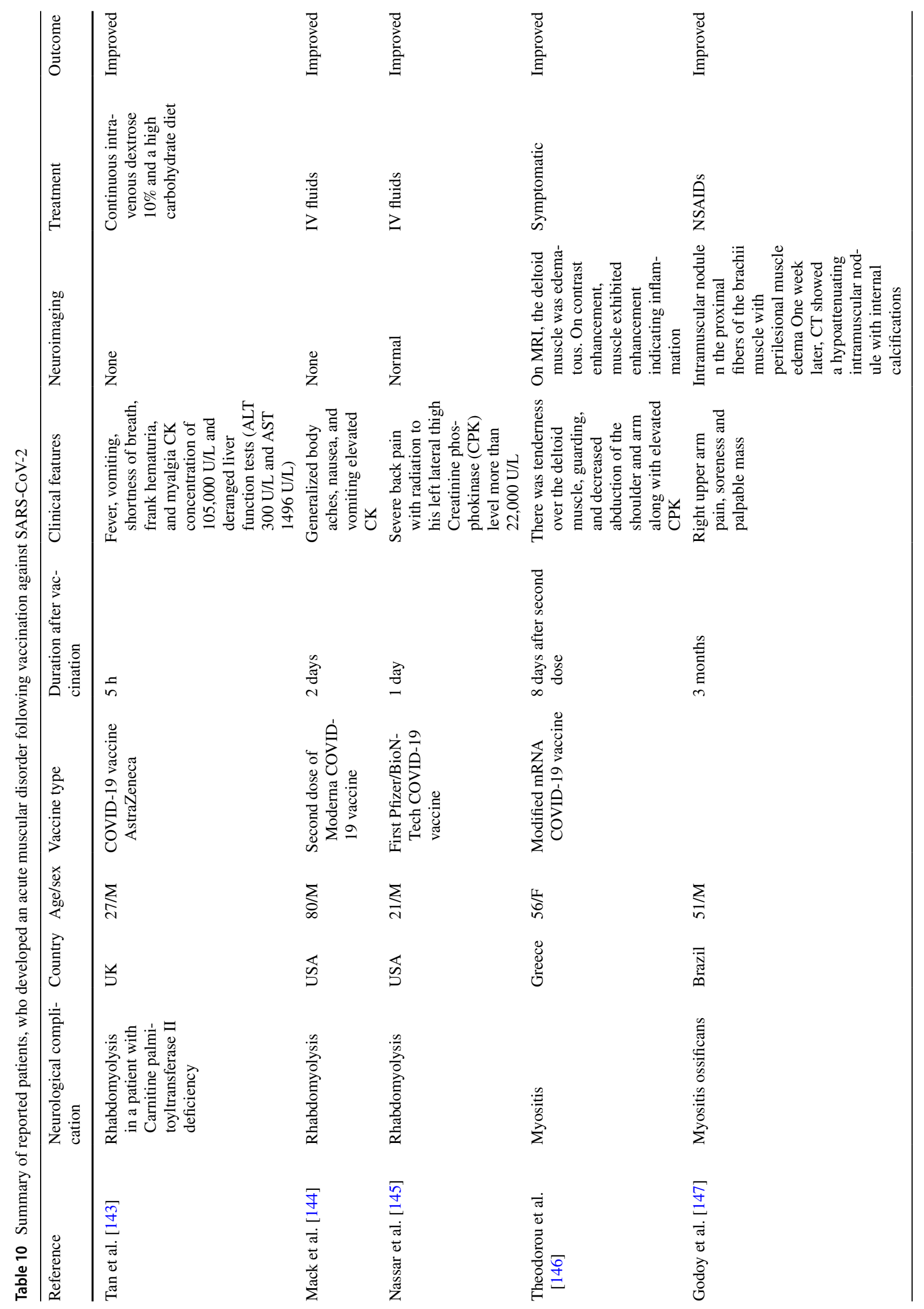


Post-vaccination Guillain-Barré syndrome generally affects older adults within 2 weeks of vaccine administration. Clinical presentation is similar to acute demyelinating neuropathy; nerve conduction studies show demyelinating pattern, and CSF examination shows cyto-albuminic dissociation. Many patients present only with facial diplegia. Response to immunotherapy is generally good. (Table 7) [110-126].

Proposed pathogenesis of Guillain-Barré syndrome is an autoantibody-mediated immunological damage of peripheral nerves via mechanism of molecular mimicry between structural components of peripheral nerves and the microorganism. Lately, several cases of Guillain-Barré syndrome following COVID-19 vaccination have also been reported.

\section{Small fiber neuropathy}

Waheed et al. described a 57-year-old female, who presented with painful neuropathy following administration of the mRNA COVID-19 vaccine. Patient subacutely presented with intense peripheral burning sensations. Electrodiagnostic studies were normal. Skin biopsy proved small fiber neuropathy. Patient responded to gabapentin.(Table 7) [127].

\section{Parsonage-Turner syndrome}

Parsonage-Turner syndrome or neuralgic amyotrophy is clinically manifested with acute unilateral shoulder pain followed by brachial plexopathy. Parsonage-Turner syndrome is usually triggered by any infection, surgery, or rarely vaccination. In many reports, Parsonage-Turner syndrome has been described following COVID-19 vaccination.(Table 8) [128-130].

\section{Herpes zoster}

Herpes zoster occurs following reactivation of varicella zoster virus. Patients with herpes zoster present with the classic maculopapular rash, which is unilateral, confined to a single dermatome. The rash disappears in 7 to 10 days. Postherpetic neuralgia is the frequent complication of herpes zoster, which is noted in 1 in 5 patients. McMahon and co-workers recorded 414 cutaneous reactions to mRNA COVID-19 vaccines, and $5(1.9 \%)$ were diagnosed with herpes zoster [131]. Other types of COVID-19 vaccines are infrequently associated with post-vaccination reactivation of herpes zoster. It has been suggested that vaccine-induced immunomodulation, resulting in dysregulation of $\mathrm{T}$ cell function, is responsible for reactivation of herpes zoster virus [132, 133]. Reports of herpes zoster reactivation after vaccine against SARS-CoV-2 are summarized in Table 9 [134-142].

\section{Myositis and rhabdomyolysis}

There are reports, which have indicated that COVID-19 vaccines have potential to damage the skeletal muscles as well (Table 10) [143-147]. Tan and colleagues described a patient with a known carnitine palmitoyltransferase-II deficiency disorder, who developed fever, vomiting, shortness of breath, frank haematuria, myalgia and muscle weakness within four hours of receiving AstraZeneca COVID19 vaccine [143]. Theodorou and colleagues described a 56-year-old woman who, 8 days after a second dose of vaccine administration, developed severe left upper arm pain along restricted shoulder movements. Her serum creatine kinase was elevated suggesting skeletal muscle damage. MRI revealed severely edematous deltoid muscles. Contrast-enhanced imaging demonstrated enhancement of deltoid muscles suggestive of myositis [146].

\section{Conclusion}

Post-authorization, a wide spectrum of serious neurological complications has been reported following COVID19 vaccination. The most devastating neurological complication is cerebral venous sinus thrombosis that has been reported in females of childbearing age following adenovector-based vaccines. Another major neurological complication of concern is Bell's palsy that was reported dominantly following mRNA vaccine administration. Transverse myelitis, acute disseminated encephalomyelitis, and Guillain-Barré syndrome are other severe unexpected post-vaccination complications that can occur as result of molecular mimicry and subsequent neuronal damage. Most of other serious neurological complications are reported in either in form of isolated case reports or small cases series. A causal association of these adverse events is controversial; large collaborative prospective studies are needed to prove causality.

\section{Declarations}

Ethical approval None

Conflict of interest The authors declare no competing interests.

\section{References}

1. World Health Organization. 12 January 2021. WHO Coronavirus (COVID-19) Dashboard. \&It; The World Health Organization https://covid19. who.int/. Accessed 1 Aug 2021. 
2. Jeff Craven. 10 June 2021. COVID-19 vaccine tracker. \&It; https://www.raps.org/news-and-articles/news-articles/2020/3/ covid-19-vaccine-tracker. Accessed 16 June 2021.

3. Piyasirisilp S, Hemachudha T (2002) Neurological adverse events associated with vaccination. Curr Opin Neurol 15(3):333-338

4. Hause AM, Gee J, Johnson T et al (2021) Anxiety-related adverse event clusters after Janssen COVID-19 vaccination - five U.S. mass vaccination sites, April 2021. MMWR Morb Mortal Wkly Rep 70(18):685-688

5. García-Grimshaw M, Ceballos-Liceaga SE, Hernández-Vanegas LE et al (2021) Neurologic adverse events among 704,003 first-dose recipients of the BNT162b2 mRNA COVID-19 vaccine in Mexico: a nationwide descriptive study. Clin Immunol 229:108786

6. Kim SH, Wi YM, Yun SY et al (2021) Adverse events in healthcare workers after the first dose of ChAdOx $1 \mathrm{nCoV}-19$ or BNT162b2 mRNA COVID-19 vaccination: a single center experience. J Korean Med Sci 36(14):e107

7. Lee YW, Lim SY, Lee JH et al (2021) Adverse reactions of the second dose of the BNT162b2 mRNA COVID-19 vaccine in healthcare workers in Korea. J Korean Med Sci. 36(21):e153

8. Göbel CH, Heinze A, Karstedt S, et al. 2021 Headache attributed to vaccination against COVID-19 (coronavirus SARS-CoV-2) with the ChAdOx1 nCoV-19 (AZD1222) vaccine: a multicenter observational cohort study [published online ahead of print, 2021 Jul 27]. Pain Ther. 1-22.

9. Module 3. Adverse events following immunization. https://www. who.int/vaccine_safety/initiative/tech_support/Part-3.pdf?ua $=1$. Accessed 19 June 2021.

10. Ng JH, Chaudhuri KR, Tan EK (2021) Functional neurological disorders and COVID-19 vaccination. Ann Neurol 90(2):328

11. Kim DD, Kung CS, Perez DL (2021) Helping the public understand adverse events associated with COVID-19 vaccinations: lessons learned from functional neurological disorder. JAMA Neurol 78(7):789-790

12. Butler M, Coebergh J, Safavi F, et al. 2021 Functional neurological disorder after SARS-CoV-2 vaccines: two case reports and discussion of potential public health implications [published online ahead of print, 2021 Jul 15]. J Neuropsychiatry Clin Neurosci. appineuropsych21050116. https://doi.org/10.1176/appi. neuropsych. 21050116

13. Ercoli T, Lutzoni L, Orofino G, Muroni A, Defazio G. 2021 Functional neurological disorder after COVID-19 vaccination [published online ahead of print, $2021 \mathrm{Jul} 29$ ]. Neurol Sci.;1-2. https://doi.org/10.1007/s10072-021-05504-8

14. Iba T, Levy JH, Warkentin TE. 2021 Recognizing vaccineinduced immune thrombotic thrombocytopenia [published online ahead of print, 2021 Jul 13]. Crit Care Med. https://doi.org/10. 1097/CCM.0000000000005211

15. Pomara C, Sessa F, Ciaccio M, et al. 2021 Post-mortem findings in vaccine-induced thrombotic thombocytopenia [published online ahead of print, 2021 May 20]. Haematologica. https://doi. org/10.3324/haematol.2021.279075.

16. Ledford H (2021) COVID vaccines and blood clots: five key questions. Nature 592(7855):495-496

17. McGonagle D, De Marco G, Bridgewood C (2021) Mechanisms of Immunothrombosis in vaccine-induced thrombotic thrombocytopenia (VITT) compared to natural SARS-CoV-2 Infection. J Autoimmun 121:102662

18. Castelli GP, Pognani C, Sozzi C, Franchini M, Vivona L (2021) Cerebral venous sinus thrombosis associated with thrombocytopenia post-vaccination for COVID-19. Crit Care 25(1):137. https://doi.org/10.1186/s13054-021-03572-y

19. D'Agostino V, Caranci F, Negro A et al (2021) A rare case of cerebral venous thrombosis and disseminated intravascular coagulation temporally associated to the COVID-19 vaccine administration. J Pers Med 11(4):285. https://doi.org/10.3390/ jpm11040285

20. Scully M, Singh D, Lown R et al (2021) Pathologic antibodies to platelet factor 4 after ChAdOx1 nCoV-19 vaccination. N Engl J Med 384(23):2202-2211. https://doi.org/10.1056/NEJMoa2105 38512

21. Franchini M, Testa S, Pezzo M et al (2021) Cerebral venous thrombosis and thrombocytopenia post-COVID-19 vaccination. Thromb Res 202:182-183. https://doi.org/10.1016/j.thromres. 2021.04.001

22. Mehta PR, Apap Mangion S, Benger M et al (2021) Cerebral venous sinus thrombosis and thrombocytopenia after COVID19 vaccination - a report of two UK cases. Brain Behav Immun 95:514-517. https://doi.org/10.1016/j.bbi.2021.04.006.11

23. Bersinger S, Lagarde K, Marlu R, Pernod G, Payen JF (2021) Using nonheparin anticoagulant to treat a near-fatal case with multiple venous thrombotic lesions during ChAdOx $1 \mathrm{nCoV}-19$ vaccination-related vaccine-induced immune thrombotic thrombocytopenia. Crit Care Med 49(9):e870-e873. https://doi.org/10. 1097/CCM.0000000000005105

24. Ramdeny S, Lang A, Al-Izzi S, Hung A, Anwar I, Kumar P. Management of a patient with a rare congenital limb malformation syndrome after SARS-CoV-2 vaccine-induced thrombosis and thrombocytopenia (VITT) [published online ahead of print, 2021 Jun 7]. Br J Haematol. 2021. https://doi.org/10.1111/bjh. 17619.

25. Zakaria Z, Sapiai NA, Ghani ARI (2021) Cerebral venous sinus thrombosis 2 weeks after the first dose of mRNA SARS-CoV-2 vaccine. Acta Neurochir (Wien) 163(8):2359-2362. https://doi. org/10.1007/s00701-021-04860-w

26. Ryan E, Benjamin D, McDonald I et al (2021) AZD1222 vaccine-related coagulopathy and thrombocytopenia without thrombosis in a young female. Br J Haematol 194(3):553-556. https:// doi.org/10.1111/bjh. 17530

27. Graf T, Thiele T, Klingebiel R, Greinacher A, Schäbitz WR, Greeve I. 2021 Immediate high-dose intravenous immunoglobulins followed by direct thrombin-inhibitor treatment is crucial for survival in Sars-Covid-19-adenoviral vector vaccine-induced immune thrombotic thrombocytopenia VITT with cerebral sinus venous and portal vein thrombosis [published online ahead of print, May 22]. J Neurol. 2021;1-3. https://doi.org/10.1007/ s00415-021-10599-2

28. George G, Friedman KD, Curtis BR, Lind SE. 2021 Successful treatment of thrombotic thrombocytopenia with cerebral sinus venous thrombosis following Ad26.COV2.S vaccination [published online ahead of print, 2021 May 14]. Am J Hematol. https://doi.org/10.1002/ajh.26237.

29. Jamme M, Mosnino E, Hayon J, Franchineau G (2021) Fatal cerebral venous sinus thrombosis after COVID-19 vaccination. Intensive Care Med 47(7):790-791. https://doi.org/10.1007/ s00134-021-06425-y

30. Tiede A, Sachs UJ, Czwalinna A, et al. Prothrombotic immune thrombocytopenia after COVID-19 vaccine [published online ahead of print, 2021 Apr 28]. Blood. 2021;blood.2021011958. https://doi.org/10.1182/blood.2021011958. 13

31. Schulz JB, Berlit P, Diener HC, Gerloff C, Greinacher A, Klein C. 2021 COVID-19 vaccine-associated cerebral venous thrombosis in Germany. medRxiv.04.30.21256383; doi: https://doi.org/ 10.1101/2021.04.30.21256383. 14

32. Bourguignon A, Arnold DM, Warkentin TE, et al. 2021 Adjunct immune globulin for vaccine-induced thrombotic thrombocytopenia [published online ahead of print, 2021 Jun 9]. N Engl J Med. https://doi.org/10.1056/NEJMoa2107051.

33. Gattringer T, Gressenberger P, Gary T, Wölfler A, Kneihsl M, Raggam RB. 2021 Successful management of vaccine-induced immune thrombotic thrombocytopenia-related cerebral sinus 
venous thrombosis after ChAdOx1 nCov-19 vaccination [published online ahead of print, 2021 Jul 8]. Stroke Vasc Neurol. svn-2021-001142. https://doi.org/10.1136/svn-2021-001142

34. Ikenberg B, Demleitner AF, Thiele T et al (2021) Cerebral venous sinus thrombosis after ChAdOx 1 nCov-19 vaccination with a misleading first cerebral MRI scan. Stroke Vasc Neurol 8:svn-2021-001095. https://doi.org/10.1136/svn-2021-001095

35. Clark RT, Johnson L, Billotti J et al (2021) Early outcomes of bivalirudin therapy for thrombotic thrombocytopenia and cerebral venous sinus thrombosis after Ad26.COV2.S vaccination. Ann Emerg Med S0196 0644(21):00342 5. https://doi.org/10. 1016/j.annemergmed.2021.04.035

36. Bonato S, Artoni A, Lecchi A, et al. 2021 Massive cerebral venous thrombosis due to vaccine-induced immune thrombotic thrombocytopenia [published online ahead of print, $2021 \mathrm{Jul} 15]$. Haematologica. https://doi.org/10.3324/haematol.2021.279246

37. Wang RL, Chiang WF, Shyu HY et al (2021) COVID-19 vaccine-associated acute cerebral venous thrombosis and pulmonary artery embolism. QJM 10:hcab185. https://doi.org/10.1093/ qjmed/hcab185

38. Dutta A, Ghosh R, Bhattacharya D et al (2021) Anti-PF4 antibody negative cerebral venous sinus thrombosis without thrombocytopenia following immunization with COVID-19 vaccine in an elderly non-comorbid Indian male, managed with conventional heparin-warfarin based anticoagulation. Diabetes Metab Syndr 15(4):102184. https://doi.org/10.1016/j.dsx.2021.06.021

39. Aladdin Y, Algahtani H, Shirah B (2021) Vaccine-induced immune thrombotic thrombocytopenia with disseminated intravascular coagulation and death following the ChAdOx1 nCoV-19 Vaccine. J Stroke Cerebrovasc Dis 30(9):105938. https://doi.org/ 10.1016/j.jstrokecerebrovasdis.2021.105938

40. Lavin M, Elder PT, O'Keeffe D, et al. Vaccine-induced immune thrombotic thrombocytopenia (VITT) - a novel clinico-pathological entity with heterogeneous clinical presentations [published online ahead of print, 2021 Jun 22]. Br J Haematol. 2021. https:// doi.org/10.1111/bjh.17613.

41. Tølbøll Sørensen AL, Rolland M, Hartmann J et al (2021) A case of thrombocytopenia and multiple thromboses after vaccination with ChAdOx1 nCoV-19 against SARS-CoV-2. Blood Adv 5(12):2569-2574. https://doi.org/10.1182/bloodadvances. 2021004904

42. Fan BE, Shen JY, Lim XR et al (2021) Cerebral venous thrombosis post BNT162b2 mRNA SARS-CoV-2 vaccination: a black swan event. Am J Hematol 96(9):E357-E361. https://doi.org/10. 1002/ajh.26272

43. Suresh P, Petchey W (2021) ChAdOx1 nCOV-19 vaccineinduced immune thrombotic thrombocytopenia and cerebral venous sinus thrombosis (CVST). BMJ Case Rep 14(6):e243931. https://doi.org/10.1136/bcr-2021-243931

44. Dias L, Soares-Dos-Reis R, Meira J et al (2021) Cerebral venous thrombosis after BNT162b2 mRNA SARS-CoV-2 vaccine. J Stroke Cerebrovasc Dis 30(8):105906. https://doi.org/10.1016/j. jstrokecerebrovasdis.2021.105906

45. Guan CY, Tsai SH, Fan JS, Lin YK, Kao CC. 2021 A rare case of a middle-age Asian male with cerebral venous thrombosis after COVID-19 AstraZeneca vaccination [published online ahead of print, Jul 8]. Am J Emerg Med. 2021;S0735-6757(21)005714. https://doi.org/10.1016/j.ajem.2021.07.011

46. Varona JF, García-Isidro M, Moeinvaziri M, Ramos-López M, Fernández-Domínguez M. 2021 Primary adrenal insufficiency associated with Oxford-AstraZeneca ChAdOx1 nCoV-19 vaccine-induced immune thrombotic thrombocytopenia (VITT) [published online ahead of print, Jul 10]. Eur J Intern Med. 2021;S0953-6205(21)00236-3. https://doi.org/10.1016/j.ejim. 2021.06.025
47. Pottegård A, Lund LC, Karlstad Ø et al (2021) Arterial events, venous thromboembolism, thrombocytopenia, and bleeding after vaccination with Oxford-AstraZeneca ChAdOx1-S in Denmark and Norway: population based cohort study. BMJ 373:n1114. https://doi.org/10.1136/bmj.n1114

48. Krzywicka K, Heldner MR, Sánchez van Kammen M et al (2021) Post-SARS-CoV-2-vaccination cerebral venous sinus thrombosis: an analysis of cases notified to the European Medicines Agency. Eur J Neurol 28(11):3656-3662. https://doi.org/10. 1111/ene. 15029

49. National Institute for Health and Care Excellence. 29 July 2021. COVID-19 rapid guideline: vaccine-induced immune thrombocytopenia and thrombosis (VTT). \&It; https://www.nice.org.uk/ guidance/ng200/resources/covid19-rapid-guideline-vaccineind uced-immune-thrombocytopenia-and-thrombosis-vitt-pdf-51036 811744. Accessed 2 Aug 2021.

50. Krzywicka K, Heldner MR, Sánchez van Kammen M et al (2021) Post-SARS-CoV-2-vaccination cerebral venous sinus thrombosis: an analysis of cases notified to the European Medicines Agency. Eur J Neurol 28(11):3656 3662. https://doi.org/10.1111/ ene. 15029

51. Bersinger S, Lagarde K, Marlu R, Pernod G, Payen JF (2021) Using nonheparin anticoagulant to treat a near-fatal case with multiple venous thrombotic lesions during ChAdOx1 nCoV-19 vaccination-related vaccine-induced immune thrombotic thrombocytopenia. Crit Care Med 49(9):e870-e873. https://doi.org/10. 1097/CCM.0000000000005105

52. Simpson CR, Shi T, Vasileiou E et al (2021) First-dose ChAdOx1 and BNT162b2 COVID-19 vaccines and thrombocytopenic, thromboembolic and hemorrhagic events in Scotland. Nat Med 27(7):1290-1297. https://doi.org/10.1038/s41591-021-01408-4

53. Athyros VG, Doumas M. 2021 A possible case of hypertensive crisis with intracranial haemorrhage after an mRNA AntiCOVID-19 vaccine [published online ahead of print, 2021 May 21]. Angiology.;33197211018323. https://doi.org/10.1177/00033 197211018323

54. Bjørnstad-Tuveng TH, Rudjord A, Anker P. 2021 Fatal cerebral haemorrhage after COVID-19 vaccine. Fatal hjerneblødning etter covid-19-vaksine. Tidsskr Nor Laegeforen. 2021;141. https://doi. org/10.4045/tidsskr.21.0312.

55. de Mélo Silva ML Jr, Lopes DP. 2021 Large hemorrhagic stroke after ChAdOx1 nCoV-19 vaccination: a case report [published online ahead of print, 2021 Jul 17]. Acta Neurol Scand. https:// doi.org/10.1111/ane.13505.

56. Bayas A, Menacher M, Christ M, Behrens L, Rank A, Naumann M (2021) Bilateral superior ophthalmic vein thrombosis, ischaemic stroke, and immune thrombocytopenia after ChAdOx 1 nCoV-19 vaccination. Lancet 397(10285):e11. https://doi.org/10. 1016/S0140-6736(21)00872-2

57. Al-Mayhani T, Saber S, Stubbs MJ et al (2021) Ischaemic stroke as a presenting feature of ChAdOx $1 \mathrm{nCoV}-19$ vaccineinduced immune thrombotic thrombocytopenia. J Neurol Neurosurg Psychiatry 92(11):1247-1248. https://doi.org/10.1136/ jnnp-2021-326984

58. Blauenfeldt RA, Kristensen SR, Ernstsen SL, Kristensen CCH, Simonsen CZ, Hvas AM (2021) Thrombocytopenia with acute ischemic stroke and bleeding in a patient newly vaccinated with an adenoviral vector-based COVID-19 vaccine. J Thromb Haemost 19(7):1771-1775. https://doi.org/10.1111/jth.15347

59 Malik B, Kalantary A, Rikabi K, Kunadi A (2021) Pulmonary embolism, transient ischaemic attack and thrombocytopenia after the Johnson \& Johnson COVID-19 vaccine. BMJ Case Rep. 14(7):e243975. https://doi.org/10.1136/bcr-2021-243975

60. Finsterer J, Korn M. 2021 Aphasia seven days after second dose of an mRNA-based SARS-CoV-2 vaccine [published online 
ahead of print, 2021 Jun 24]. Brain Hemorrhages. https://doi. org/10.1016/j.hest.2021.06.001.

61. Walter U, Fuchs M, Grossmann A, et al. 2021 Adenovirusvectored COVID-19 vaccine-induced immune thrombosis of carotid artery: a case report [published online ahead of print, 2021 Jul 26]. Neurology. https://doi.org/10.1212/WNL.00000 00000012576.

62. Baldelli L, Amore G, Montini A et al (2021) Hyperacute reversible encephalopathy related to cytokine storm following COVID-19 vaccine. J Neuroimmunol 358:577661. https://doi. org/10.1016/j.jneuroim.2021.577661

63. Aladdin Y, Shirah B (2021) New-onset refractory status epilepticus following the ChAdOx1 nCoV-19 vaccine. J Neuroimmunol 357:577629. https://doi.org/10.1016/j.jneuroim.2021. 577629

64. Ghosh R, Dubey S, Roy D, Mandal A, Naga D, Benito-León J (2021) Focal onset non-motor seizure following COVID19 vaccination: a mere coincidence? Diabetes Metab Syndr 15(3):1023-1024. https://doi.org/10.1016/j.dsx.2021.05.003

65. Liu BD, Ugloini C, Jha P (2021) Two cases of post-Moderna COVID-19 vaccine encephalopathy associated with nonconvulsive status epilepticus. Cureus 13(7):e16172. https://doi.org/10. $7759 /$ cureus. 16172

66. Naharci MI, Tasci I. 2021 Delirium in a patient with Alzheimer's dementia following COVID-19 vaccination [published online ahead of print, 2021 Jul 10]. Psychogeriatrics. https://doi.org/ 10.1111/psyg.12747.

67. Salinas MR, Dieppa M (2021) Transient akathisia after the SARS-Cov-2 vaccine. Clin Park Relat Disord 4:100098. https:// doi.org/10.1016/j.prdoa.2021.100098

68. Zavala-Jonguitud LF, Pérez-García CC (2021) Delirium triggered by COVID-19 vaccine in an elderly patient. Geriatr Gerontol Int 21(6):540. https://doi.org/10.1111/ggi.14163

69. Alfishawy M, Bitar Z, Elgazzar A, Elzoueiry M. 2021 Neuroleptic malignant syndrome following COVID-19 vaccination [published online ahead of print, Feb 20]. Am J Emerg Med. 2021;S0735-6757(21)00117-0. https://doi.org/10.1016/j.ajem. 2021.02.011

70. Ozgen Kenangil G, Ari BC, Guler C, Demir MK (2021) Acute disseminated encephalomyelitis-like presentation after an inactivated coronavirus vaccine. Acta Neurol Belg 121(4):1089-1091. https://doi.org/10.1007/s13760-021-01699-x

71. Cao L, Ren L (2021) Acute disseminated encephalomyelitis after severe acute respiratory syndrome coronavirus 2 vaccination: a case report. Acta Neurol Belg 1:1-3. https://doi.org/10.1007/ s13760-021-01608-2

72. Raknuzzaman M, Jannaty T, Hossain MB, Saha B, Dey SK, Shahidullah M. 2021 Post Covid 19 vaccination acute disseminated encephalomyelitis: a case report in Bangladesh. Int J Med Sci Clin Res Studies 3. https://doi.org/10.47191/ijmscrs/v1-i3-01

73. Torrealba-Acosta G, Martin JC, Huttenbach Y et al (2021) Acute encephalitis, myoclonus and Sweet syndrome after mRNA-1273 vaccine. BMJ Case Rep 14(7):e243173. https://doi.org/10.1136/ bcr-2021-243173

74. Vogrig A, Janes F, Gigli GL (2021) Acute disseminated encephalomyelitis after SARS-CoV-2 vaccination. Clin Neurol Neurosurg 208:106839. https://doi.org/10.1016/j.clineuro.2021.106839

75. Zuhorn F, Graf T, Klingebiel R, Schäbitz WR, Rogalewski A (2021) Postvaccinal encephalitis after ChAdOx1 nCov-19. Ann Neurol 90(3):506-511. https://doi.org/10.1002/ana.26182

76. Pellegrino P, Carnovale C, Perrone V et al (2013) Acute disseminated encephalomyelitis onset: evaluation based on vaccine adverse events reporting systems. PLoS One 8(10):e77766. https://doi.org/10.1371/journal.pone.0077766

77. Malhotra SH, Gupta P, Prabhu V, Garg RK, Dandu H, Agarwal V. COVID-19 vaccination-associated myelitis [published online ahead of print, 2021 Mar 31]. QJM. 2021;hcab069. https://doi. org/10.1093/qjmed/hcab069

78. Fitzsimmons, William and Nance, Christopher S., Sudden onset of myelitis after COVID-19 vaccination: an under-recognized severe rare adverse event (May 5, 2021). Available at SSRN: https://ssrn.com/abstract=3841558 or https://doi.org/10.2139/ ssrn. 3841558

79. Tahir N, Koorapati G, Prasad S et al (2021) SARS-CoV-2 vaccination-induced transverse myelitis. Cureus 13(7):e16624. https:// doi.org/10.7759/cureus.16624

80. Pagenkopf C, Südmeyer M (2021) A case of longitudinally extensive transverse myelitis following vaccination against Covid-19. J Neuroimmunol 358:577606. https://doi.org/10.1016/j.jneuroim. 2021.577606

81. Helmchen C, Buttler GM, Markewitz R, Hummel K, Wiendl H, Boppel T. 2021 Acute bilateral optic/chiasm neuritis with longitudinal extensive transverse myelitis in longstanding stable multiple sclerosis following vector-based vaccination against the SARS-CoV-2 [published online ahead of print, Jun 15]. J Neurol. 2021;1-6. https://doi.org/10.1007/s00415-021-10647-x

82. Havla J, Schultz Y, Zimmermann H, Hohlfeld R, Danek A, Kümpfel T. 2021 First manifestation of multiple sclerosis after immunization with the Pfizer-BioNTech COVID-19 vaccine [published online ahead of print, 2021 Jun 11]. J Neurol. 1-4. https://doi.org/10.1007/s00415-021-10648-w

83. Chen S, Fan XR, He S, Zhang JW, Li SJ (2021) Watch out for neuromyelitis optica spectrum disorder after inactivated virus vaccination for COVID-19. Neurol Sci 42(9):3537-3539. https:// doi.org/10.1007/s10072-021-05427-4

84. Chagla Z (2021) In adults, the Oxford/AstraZeneca vaccine had $70 \%$ efficacy against COVID-19 $>14 \mathrm{~d}$ after the 2 nd dose. Ann Intern Med 174(3):JC29. https://doi.org/10.7326/ACPJ202103 160-029

85. Knoll MD, Wonodi C (2021) Oxford-AstraZeneca COVID-19 vaccine efficacy. Lancet 397(10269):72-74. https://doi.org/10. 1016/S0140-6736(20)32623-4

86. Román GC, Gracia F, Torres A, Palacios A, Gracia K, Harris D (2021) Acute transverse myelitis (ATM):clinical review of 43 patients with COVID-19-associated ATM and 3 post-vaccination ATM serious adverse events with the ChAdOx1 nCoV-19 vaccine (AZD1222). Front Immunol 26(12):653786. https://doi.org/ 10.3389/fimmu.2021.653786.PMID:33981305;PMCID:PMC81 07358

87. Shemer A, Pras E, Hecht I (2021) Peripheral facial nerve palsy following BNT162b2 (COVID-19) vaccination. Isr Med Assoc J 23(3): 143-144 (PMID: 33734623)

88. Repajic M, Lai XL, Xu P, Liu A (2021) Bell's Palsy after second dose of Pfizer COVID-19 vaccination in a patient with history of recurrent Bell's palsy. Brain Behav Immun Health 13:100217. https://doi.org/10.1016/j.bbih.2021.100217

89. Colella G, Orlandi M, Cirillo N. 2021 Bell's palsy following COVID-19 vaccination [published online ahead of print, 2021 Feb 21]. J Neurol. 1-3. doi:https://doi.org/10.1007/ s00415-021-10462-4

90. Martin-Villares C, Vazquez-Feito A, Gonzalez-Gimeno MJ, de la Nogal-Fernandez B. 2021 Bell's palsy following a single dose of mRNA SARS-CoV-2 vaccine: a case report [published online ahead of print, 2021 May 25]. J Neurol. 1-2. doi:https://doi.org/ 10.1007/s00415-021-10617-3

91. Nishizawa Y, Hoshina Y, Baker V. 2021 Bell's palsy following the Ad26.COV2.S COVID-19 vaccination [published online ahead of print, 2021 May 20]. QJM.;hcab143. doi:https://doi.org/ 10.1093/qjmed/hcab143

92. Gómez de Terreros Caro G, Díaz SG, Alé MP, Gimeno LM. 2021 PARÁLISIS DE BELL TRAS VACUNACIÓN COVID19: A PROPÓSITO DE UN CASO [BELL'S PALSY FOLLOWING 
COVID-19 VACCINATION: A CASE REPORT] [published online ahead of print, 2021 Apr 12]. Neurologia (Engl Ed). https://doi.org/10.1016/j.nrl.2021.04.004

93. Burrows A, Bartholomew T, Rudd J, Walker D (2021) Sequential contralateral facial nerve palsies following COVID-19 vaccination first and second doses. BMJ Case Rep. 14(7):e243829. https://doi.org/10.1136/bcr-2021-243829

94. Obermann M, Krasniqi M, Ewers N, Fayad J, Haeberle U (2021) Bell's palsy following COVID-19 vaccination with high CSF antibody response. Neurol Sci 42(11):4397-4399. https://doi.org/ 10.1007/s10072-021-05496-5

95. Iftikhar H, Noor SU, Masood M et al (2021) Bell's palsy after 24 hours of mRNA-1273 SARS-CoV-2 vaccine. Cureus 13(6):e15935. https://doi.org/10.7759/cureus. 15935

96. Ozonoff A, Nanishi E, Levy O. 2021 Bell's palsy and SARSCoV-2 vaccines-an unfolding story - authors' reply [published online ahead of print, 2021 Jun 7]. Lancet Infect Dis S14733099(21)00323-6. doi:https://doi.org/10.1016/S1473-3099(21) 00323-6

97. Shemer A, Pras E, Einan-Lifshitz A, Dubinsky-Pertzov B, Hecht I (2021) Association of COVID-19 vaccination and facial nerve palsy: a case-control study. JAMA Otolaryngol Head Neck Surg 147(8):739-743. https://doi.org/10.1001/jamaoto.2021.1259

98. Ozonoff A, Nanishi E, Levy O (2021) Bell's palsy and SARSCoV-2 vaccines. Lancet Infect Dis 21(4):450-452. https://doi. org/10.1016/S1473-3099(21)00076-1

99. Konstantinidis I, Tsakiropoulou E, Hähner A, de With K, Poulas K, Hummel T. 2021 Olfactory dysfunction after coronavirus disease 2019 (COVID-19) vaccination [published online ahead of print, 2021 May 28]. Int Forum Allergy Rhinol. https://doi. org/10.1002/alr.22809.

100. Keir G, Maria NI, Kirsch CFE (2021) Unique imaging findings of neurologic phantosmia following Pfizer-BioNtech COVID-19 vaccination: a case report. Top Magn Reson Imaging 30(3):133137. https://doi.org/10.1097/RMR.0000000000000287

101. Reyes-Capo DP, Stevens SM, Cavuoto KM. 2021 Acute abducens nerve palsy following COVID-19 vaccination [published online ahead of print, 2021 May 24]. J AAPOS S1091-8531(21)001099. doi:https://doi.org/10.1016/j.jaapos.2021.05.003

102. Parrino D, Frosolini A, Gallo C, De Siati RD, Spinato G, de Filippis C (2021) Tinnitus following COVID-19 vaccination: report of three cases. Int J Audiol 13:1-4

103. Tseng PT, Chen TY, Sun YS, Chen YW, Chen JJ. 2021 The reversible tinnitus and cochleopathy followed first-dose AstraZeneca COVID-19 vaccination [published online ahead of print, 2021 Jul 23]. QJM hcab210. doi:https://doi.org/10.1093/qjmed/ hcab210

104 Narasimhalu K, Lee WC, Salkade PR, De Silva DA (2021) Trigeminal and cervical radiculitis after tozinameran vaccination against COVID-19. BMJ Case Rep 14(6):e242344. https:// doi.org/10.1136/bcr-2021-242344

105. Wichova H, Miller ME, Derebery MJ (2021) Otologic manifestations after COVID-19 vaccination: the house ear clinic experience. Otol Neurotol 42(9):e1213-e1218. https://doi.org/10.1097/ MAO.0000000000003275

106. Santovito LS, Pinna G (2021) Acute reduction of visual acuity and visual field after Pfizer-BioNTech COVID-19 vaccine 2nd dose: a case report. Inflamm Res 70(9):931-933. https://doi.org/ 10.1007/s00011-021-01476-9

107. Dyer O (2021) Covid-19: Regulators warn that rare GuillainBarré cases may link to J\&J and AstraZeneca vaccines. BMJ 374:n1786. https://doi.org/10.1136/bmj.n1786

108. Márquez Loza AM, Holroyd KB, Johnson SA, Pilgrim DM, Amato AA. Guillain- Barré syndrome in the placebo and active arms of a COVID-19 vaccine clinical trial: temporal associations do not imply causality [published online ahead of print,
2021 Apr 6]. Neurology. 2021. https://doi.org/10.1212/WNL. 0000000000011881.

109. FDA Briefing Document Janssen Ad26.COV2.S Vaccine for the prevention of COVID-1.26 February 2021. Vaccines and Related Biological Products Advisory Committee Meeting. \&It; https://www.fda.gov/media/146217/download. Accessed 24 June 2021

110 Waheed S, Bayas A, Hindi F, Rizvi Z, Espinosa PS (2021) Neurological complications of COVID-19: Guillain-Barre syndrome following Pfizer COVID-19 vaccine. Cureus. 13(2):e13426. https://doi.org/10.7759/cureus.13426

111. Márquez Loza AM, Holroyd KB, Johnson SA, Pilgrim DM, Amato AA. 2021 Guillain-Barré syndrome in the placebo and active arms of a COVID-19 vaccine clinical trial: temporal associations do not imply causality [published online ahead of print, 2021 Apr 6]. Neurology. https://doi.org/10.1212/WNL.00000 00000011881.

112 Patel SU, Khurram R, Lakhani A, Quirk B (2021) Guillain-Barre syndrome following the first dose of the chimpanzee adenovirus-vectored COVID-19 vaccine, ChAdOx1. BMJ Case Rep. 14(4):e242956. https://doi.org/10.1136/bcr-2021-242956

113. Razok A, Shams A, Almeer A et al. 2021 Post-COVID-19 vaccine Guillain-Barré syndrome; first reported case from Qatar. Authorea. May 07,. DOI: https://doi.org/10.22541/au.16204 $1666.65803989 / \mathrm{v} 1$

114. Ogbebor O, Seth H, Min Z, Bhanot N (2021) Guillain-Barré syndrome following the first dose of SARS-CoV-2 vaccine: a temporal occurrence, not a causal association. IDCases 24:e01143. https://doi.org/10.1016/j.idcr.2021.e01143

115. Finsterer J (2021) Exacerbating Guillain-Barré syndrome eight days after vector-based COVID-19 vaccination. Case Rep Infect Dis 2021:3619131. https://doi.org/10.1155/2021/3619131

116. Maramattom BV, Krishnan P, Paul R et al (2021) Guillain-Barré syndrome following ChAdOx 1-S/nCoV-19 vaccine. Ann Neurol 90(2):312-314. https://doi.org/10.1002/ana.26143

117. Allen CM, Ramsamy S, Tarr AW, Tighe PJ, Irving WL, Tanasescu R, Evans JR (2021) Guillain-Barré syndrome variant occurring after SARS-CoV-2 vaccination. Ann Neurol. https://doi.org/ 10.1002/ana.26144

118. Kohli S, Varshney M, Mangla S, Jaiswal B, Chhabra PH (2021) Guillain-Barré syndrome after COVID-19 vaccine: should we assume a causal Link? International Journal of Medical and Pharmaceutical Case Reports 14(1):20-24. https://doi.org/10.9734/ ijmpcr/2021/v14i130124

119. Azam S, Khalil A, Taha A (2021) Guillain-Barré syndrome in a 67-year-old male post COVID-19 vaccination (Astra Zeneca). American Journal of Medical Case Reports 9(8):424-427

120 Hasan T, Khan M, Khan F, Hamza G (2021) Case of GuillainBarré syndrome following COVID-19 vaccine. BMJ Case Rep 14(6):e243629. https://doi.org/10.1136/bcr-2021-243629

121. Theuriet J, Richard C, Becker J, Pegat A, Bernard E, Vukusic S. 2021 Guillain-Barré syndrome following first injection of ChAdOx1 nCoV-19 vaccine: First report. Rev Neurol (Paris) S0035-3787(21)00585-3 doi:https://doi.org/10.1016/j.neurol. 2021.04.005

122. Bonifacio GB, Patel D, Cook S, et al. 2021 Bilateral facial weakness with paraesthesia variant of Guillain-Barré syndrome following Vaxzevria COVID-19 vaccine [published online ahead of print, 2021 Jul 14]. J Neurol Neurosurg Psychiatry jnnp-2021327027. doi:https://doi.org/10.1136/jnnp-2021-327027

123. Nasuelli NA, De Marchi F, Cecchin M et al (2021) A case of acute demyelinating polyradiculoneuropathy with bilateral facial palsy after ChAdOx1 nCoV-19 vaccine. Neurol Sci 42(11):47474749. https://doi.org/10.1007/s10072-021-05467-w

124. Jain E, Pandav K, Regmi P et al (2021) Facial diplegia: a rare, atypical variant of Guillain-Barré syndrome and Ad26.COV2.S 
Vaccine. Cureus 13(7):e16612. https://doi.org/10.7759/cureus. 16612

125 McKean N, Chircop C (2021) Guillain-Barré syndrome after COVID-19 vaccination. BMJ Case Rep 14(7):e244125. https:// doi.org/10.1136/bcr-2021-244125

126. Bonifacio GB, Patel D, Cook S, et al. 2021 Bilateral facial weakness with paraesthesia variant of Guillain-Barré syndrome following Vaxzevria COVID-19 vaccine [published online ahead of print, 2021 Jul 14]. J Neurol Neurosurg Psychiatry jnnp-2021327027. doi:https://doi.org/10.1136/jnnp-2021-327027

127. Waheed W, Carey ME, Tandan SR, Tandan R (2021) Post COVID-19 vaccine small fiber neuropathy. Muscle Nerve 64(1):E1-E2. https://doi.org/10.1002/mus.27251

128. Mahajan S, Zhang F, Mahajan A, Zimnowodzki S (2021) Parsonage Turner syndrome after COVID-19 vaccination. Muscle Nerve 64(1):E3-E4. https://doi.org/10.1002/mus.27255

129. Diaz-Segarra N, Edmond A, Gilbert C, Mckay O, Kloepping C, Yonclas P. 2021 Painless idiopathic neuralgic amyotrophy after COVID-19 vaccination: a case report [published online ahead of print, 2021 Apr 22]. PM R.;https://doi.org/10.1002/pmrj.12619

130. Antonio Crespo Burillo J, Martínez CL, Arguedas CG, Pueyo FJM (2021) Neuralgia amiotrófica secundaria a vacuna contra COVID-19 Vaxzevria (AstraZeneca) [Amyotrophic neuralgia secondary to Vaxzevria (AstraZeneca) COVID-19 vaccine]. Neurologia 36(7):571-572. https://doi.org/10.1016/j.nrl.2021. 05.007

131. McMahon DE, Amerson E, Rosenbach M et al (2021) Cutaneous reactions reported after Moderna and Pfizer COVID-19 vaccination: a registry-based study of 414 cases. J Am Acad Dermatol 85(1):46-55. https://doi.org/10.1016/j.jaad.2021.03.092

132. Arora P, Sardana K, Mathachan SR, Malhotra P. 2021 Herpes zoster after inactivated COVID-19 vaccine: a cutaneous adverse effect of the vaccine [published online ahead of print, 2021 Jun 2]. J Cosmet Dermatol. https://doi.org/10.1111/jocd.14268.

133. Lladó I, Fernández-Bernáldez A, Rodríguez-Jiménez P 2021. "Varicella zoster virus reactivation and mRNA vaccines as a trigger". Reply to: Herpes-Zoster reactivation after mRNA-1273 (Moderna) SARS-CoV-2 Vaccination [published online ahead of print, 2021 Jul 22]. JAAD Case Rep. https://doi.org/10.1016/j. jdcr.2021.07.011.

134. Tessas I, Kluger N (2021) Ipsilateral herpes zoster after the first dose of BNT162b2 mRNA COVID-19 vaccine. J Eur Acad Dermatol Venereol 35(10):e620-e622. https://doi.org/10.1111/jdv. 17422

135. Rodríguez-Jiménez P, Chicharro P, Cabrera LM et al (2021) Varicella-zoster virus reactivation after SARS-CoV-2 BNT162b2 mRNA vaccination: Report of 5 cases. JAAD Case Rep 12:5859. https://doi.org/10.1016/j.jdcr.2021.04.014

136. Eid E, Abdullah L, Kurban M, Abbas O (2021) Herpes zoster emergence following mRNA COVID-19 vaccine. J Med Virol. https://doi.org/10.1002/jmv.27036
137. Bostan E, Yalici-Armagan B (2021) Herpes zoster following inactivated COVID-19 vaccine: a coexistence or coincidence? J Cosmet Dermatol 20(6):1566-1567. https://doi.org/10.1111/ jocd. 14035

138. Furer V, Zisman D, Kibari A, Rimar D, Paran Y, Elkayam O. 2021 Herpes zoster following BNT162b2 mRNA Covid-19 vaccination in patients with autoimmune inflammatory rheumatic diseases: a case series [published online ahead of print, 2021 Apr 12]. Rheumatology (Oxford) keab345. doi:https://doi.org/ 10.1093/rheumatology/keab345

139. Aksu SB, Öztürk GZ (2021) A rare case of shingles after COVID-19 vaccine: is it a possible adverse effect? Clin Exp Vaccine Res 10(2):198-201. https://doi.org/10.7774/cevr.2021. 10.2.198

140. Chiu HH, Wei KC, Chen A, Wang WH. 2021 Herpes zoster following COVID-19 vaccine: report of 3 cases [published online ahead of print, 2021 Jul 22]. QJM.;hcab208. https://doi.org/10. 1093/qjmed/hcab208

141. Alpalhão M, Filipe P (2021) Herpes Zoster following SARSCoV-2 vaccination - a series of 4 cases. J Eur Acad Dermatol Venereol 35(11):e750-e752. https://doi.org/10.1111/jdv.17555

142 Channa L, Torre K, Rothe M (2021) Letter to the editor: HerpesZoster reactivation after mRNA-1273 (Moderna) SARS-CoV-2 Vaccination. JAAD Case Rep 15:60-61. https://doi.org/10. 1016/j.jdcr.2021.05.042

143. Tan A, Stepien KM, Narayana STK (2021) Carnitine palmitoyltransferase II deficiency and post-COVID vaccination rhabdomyolysis. QJM 19:hcab077. https://doi.org/10.1093/qjmed/hcab077

144 Mack M, Nichols L, Guerrero DM (2021) Rhabdomyolysis secondary to COVID-19 vaccination. Cureus 13(5):e15004. https:// doi.org/10.7759/cureus. 15004

145 Nassar M, Chung H, Dhayaparan Y et al (2021) COVID-19 vaccine induced rhabdomyolysis: Case report with literature review. Diabetes Metab Syndr. 15(4):102170. https://doi.org/10.1016/j. dsx.2021.06.007

146 Theodorou DJ, Theodorou SJ, Axiotis A, Gianniki M, Tsifetaki N (2021) COVID-19 vaccine-related myositis. QJM 1146(424):425. https://doi.org/10.1093/qjmed/hcab043

147. Godoy IRB, Rodrigues TC, Skaf A (2021) Myositis ossificans following COVID-19 vaccination. QJM 9:hcab161. https://doi. org/10.1093/qjmed/hcab161

Publisher's note Springer Nature remains neutral with regard to jurisdictional claims in published maps and institutional affiliations. 